\title{
Historia arquitectónica de Tarapacá: estrategias residenciales y formación de asentamientos, Siglos X AC a XVII DC (Andes Centro Sur)
}

\section{Architectural history of Tarapacá: residential strategies and settlement formation, Xth Century BC - XVIIth Century AD (South Central Andes)}

\author{
Simón Urbina A. ${ }^{1}$, Leonor Adán A. ${ }^{2}$, Constanza Pellegrino H. ${ }^{3}$ \\ y Roberto Izaurieta S. J. ${ }^{4}$
}

\section{Resumen}

El presente trabajo sintetiza el estudio de patrones arquitectónicos residenciales y asentamientos para la región de Tarapacá entre los siglos X AC y XVII DC. La distribución, variabilidad y transformaciones de los sitios expresa una tendencia en donde los patrones formales de las estructuras domésticas resultan indicadores de cambios graduales o radicales en la organización/estructura social de las comunidades tarapaqueńas durante el período Formativo, Intermedio Tardío e Inca-Colonial. La propuesta teórica y el análisis hacen consistente el estudio inter-sitio de la arquitectura prehispánica, en ámbitos de excelente preservación superficial, utilizando una metodología estandarizada. La investigación valoriza una estrategia de trabajo interdisciplinaria y ofrece una lectura sistemática del comportamiento de la arquitectura doméstica para comprender la historia regional de los Andes Centro-Sur.

Palabras claves: arquitectura doméstica, arqueología de asentamientos, región de Tarapacá, Andes Centro-Sur.

\begin{abstract}
This paper presents a regional synthesis of settlements and residential building patterns in Tarapacá region, between Xth BC and XVIIth AD centuries. Distribution, variability and transformations on sites plans and domestic space design shows a long-term process, where the formal patterns of the domestic structures reveal gradual or radical changes in the organization or social structure of local communities during the Formative, Late Intermediate and IncaColonial period. Theoretical framework and settlement analysis allow us an inter-site perspective of pre-Hispanic architecture in areas of excellent material preservation, using a standardized methodology. The research points out the potential of systematic reading of domestic architecture's behaviour to understand long term regional history in South-Central Andes.
\end{abstract}

Keywords: domestic architecture, settlement archaeology, Tarapacá Region, SouthCentral Andes.

Recibido: 2 mayo 2016. Aceptado: 8 marzo 2017

1 Laboratorio de Arqueología, Dirección Museológica, Universidad Austral de Chile. Valdivia, CHILE. Email: simon.urbina@uach.cl.

2 Dirección Museológica, Universidad Austral de Chile. Valdivia, CHILE. Email: ladan@ uach.cl.

3 Programa Doctorado en Antropología. UCN-UTA, Universidad Católica del Norte. San Pedro de Atacama, CHILE. E-mail: constanza.pellegrino@alumnos.ucn.cl.

4 Departamento de Antropología, Universidad de Chile. Santiago, CHILE. Email: rizaurie@ uchile.cl. 


\section{Introducción}

El presente trabajo propone una interpretación de la historia tarapaqueña basada en una síntesis regional de indicadores arquitectónicos relativos a asentamientos y unidades domésticas. La primera parte del trabajo discute el marco teórico y metodológico que ha guiado las investigaciones regionales sobre asentamientos en los distintos ámbitos biogeográficos del desierto de Atacama, proponiendo un acercamiento sistemático, sociológico e histórico a la arquitectura prehispánica, que se basa en la operatividad de variables y conceptos claves como patrón de asentamiento, tradición arquitectónica y componentes constructivos.

Los resultados del análisis sincrónico y diacrónico de los indicadores y atributos permiten por primera vez un nivel de integración y comparación a nivel inter-sitio de escala regional desde el período Formativo hasta inicios del período Colonial (siglos IX AC a XVII DC), utilizando la unidad doméstica como elemento principal de esta comparación. Una lectura crítica del proceso formativo de sedentarización, el surgimiento de poblados aglutinados y arquitectura pública, así como la dispersión ecológica y abandono de asentamientos a lo largo del período Intermedio Tardío permiten discutir la secuencia cronológica regional desde una perspectiva de larga duración, donde las transformaciones arquitectónicas plantean modificaciones en los patrones residenciales de las comunidades tarapaqueñas.

Para mayor resolución de los cambios históricos significativos percibidos a nivel de los asentamientos y zonas biogeográficas, se categorizan los patrones de vivienda que cruzan el lapso temporal analizado, asumiendo la tesis de Amos Rapoport (1972, p. 65) según la cual la vivienda no es solo una estructura que provee protección y techo, sino un espacio funcionalmente complejo y una institución social básica de la vida de los pueblos, razón por la cual los cambios dispuestos en ella suponen transformaciones en la estructura general de relaciones sociales.

\section{Arquitectura como indicador de cambio histórico}

La premisa básica sobre la cual se asienta el ejercicio interpretativo de la arqueología de asentamientos es que la ocurrencia de prácticas reiteradas en espacios habitados y construidos crea patrones materiales reconocibles (Yaeger y Canuto, 2000, pp. 1-15). Empleados comúnmente para realizar inferencias sobre organización política, social y religiosa de las culturas, los estudios arqueológicos utilizan esta unidad, el asentamiento, como base del análisis histórico y antropológico (Chang, 1976), puesto que esta categoría corresponde a la unidad sociológica mínima y un referente de las comunidades humanas y los distintos espacios habitados por ellas (Chang, 1968, pp. 3 y 27; Trigger, 1968; Rapoport, 1972).

Como indica Canziani (2009, p. 28), en cualquiera de sus etapas o períodos, la historia de la arquitectura y el urbanismo prehispánico en los Andes debe considerar evaluar y explicar las relaciones hipotéticas de correspondencia entre formación social y formas de asentamiento. En este plano, las modalidades sincrónicas y diacrónicas que adoptan las formaciones sociales podrán ser definidas a partir de la correlación entre los tipos de vivienda y las formas de parentesco, así como los planos de los asentamientos se corresponden con la organización social de una comunidad aldeana o un Estado (Willey, 1968, p. 217). ${ }^{5}$

Precisamente, el análisis arqueológico de la arquitectura y los patrones de asentamiento constituyen el procedimiento básico de la disciplina para la reconstrucción de las relaciones sociales y políticas, entendiendo que los atributos tecnológicos, de diseño y el ordenamiento de las estructuras de una aldea o ciudad y su emplazamiento condicionan las relaciones de poder y regulan la conducta de los distintos agentes que las construyen y utilizan (Nielsen, 1995). Las cualidades físicas y simbólicas de los edificios, como elementos transmisores de información, identifican, al modo de "diacríticos culturales", a sus ocupantes en su vida cotidiana. Dichas

5 Véanse las definiciones, indicadores y resultados de la aplicación de este marco analítico en Adán et al., 2007; Adán y Urbina, 2010; Urbina et al., 2011, 2012a. 
cualidades aluden, en la práctica, a cierto "poder de acción" o "capitales" (Nielsen, 1995, en referencia a Bourdieu, 1977) que ciertos grupos o individuos poseen o aspiran poseer dentro del ámbito mayor al de su propia familia o red de parentesco más cercana (Urbina et al., 2012a, p. 33).

Por estas razones, el estudio del período Formativo en el desierto de Atacama involucra el desafío de comprender cómo las sociedades domesticaron la naturaleza a través de distintos procesos tecnológicos, cómo surgieron nuevas concepciones sobre naturaleza y cultura y cómo la vida social fue domesticada y transformada mediante dispositivos de naturaleza arquitectónica.

En este trabajo utilizaremos el concepto historia ocupacional referido a la comprensión integral de los asentamientos en un contexto regional, los rangos de variabilidad arquitectónica intra-sitio y patrones de uso del espacio en distintos niveles o escalas. Este concepto se inspira en el trabajo de Gary Urton " $\mathrm{La}$ arquitectura pública como texto social...” (1988), a partir del cual planteamos una lectura arqueológica de las transformaciones arquitectónicas y cambios en la vida social de las viviendas en una región particular, en el entendido que las conductas humanas y los eventos históricos adquieren significado sólo cuando los contextos diacrónicos son evaluados en un marco espacial extenso (Trigger, 1981, p. 85; Knapp, 1992, p. 6).

Siguiendo la conceptualización de Willey y Phillip (1958), por tradición arquitectónica entendemos la continuidad de ciertas configuraciones tecnológicas -técnicas, diseños, modos de hacer- que permiten vincular semejanzas, adaptaciones o diferencias entre tipos de edificios de un asentamiento desde una perspectiva intra e inter-sitio. Esta definición de tradición acepta modalidades arquitectónicas heterogéneas a nivel regional o dentro de un mismo asentamiento, tanto a nivel sincrónico como diacrónico, puesto que asume la permanente estructuración de la vida doméstica y los procesos históricos donde las tradiciones son recreadas o sustancialmente modificadas (Salazar, 2008). Las Tradiciones Arquitectónicas que hemos definido para explicar la historia ocupacional de Tarapacá reciben los nombres siguientes: 1) en Piedra o Temprana, 2) de Oasis en Barro, 3) en Anhidrita o Caliche, 4) Quebradeña o de Tierras Altas (Adán y Urbina, 2010, pp. 866-871; Adán et al., 2013, pp. 76-78), a las cuales debiéramos agregar una quinta Tradición Tardía o Incaica.

La coherencia y variaciones dentro de las tradiciones arquitectónicas en los Andes van a referir a un conjunto de conocimientos vernáculos que se expresan en la convergencia o divergencia de ciertos componentes constructivos conspicuos, ya sean formatos o soluciones aplicadas al emplazamiento o acondicionamiento de espacios residenciales, ceremoniales o productivos. Los análisis que hemos efectuado en Tarapacá señalan que en ocasiones dentro de dos o más Tradiciones Arquitectónicas se comparten, heredan o modifican sutilmente ciertos componentes constructivos, como por ejemplo el uso de estructuras semisubterráneas, el uso de pilares funcionales, esquinas curvas en las viviendas o el aterrazamiento del terreno, situaciones que pueden ser correlacionadas con la eficacia de ciertas tecnologías de edificación, identidades emergentes, pertenencia étnica o interacción económica (Stanish, 1989; Muñoz, 1993) (Figura 1a-b).

Como indica Bermann (1993, pp. 14-15), debido a que el estudio de las sociedades complejas en los Andes se ha centrado en el estudio de grandes transformaciones políticas a nivel regional, se hace necesario instalar una perspectiva braudeliana centrada en la vida doméstica para evaluar, desde indicadores microhistóricos, el real impacto de los cambios detectados en viviendas y asentamientos arqueológicos, que son el espacio donde las relaciones cara a cara ocurren. El autor plantea, desde sus investigaciones en la cuenca del lago Titicaca, que no siempre los cambios históricos a nivel regional provocaron cambios inmediatos en los espacios domésticos de la población común. Esto implica que las transformaciones, innovaciones o emergencia de nuevas estructuras sociales pueden manifestarse a través de ritmos históricos diferentes a partir del estudio de la arquitectura de asentamientos a escala regional y local.

El interés por la historia de los recintos (edificios) y la disposición de rasgos derivados de la actividad doméstica ha sido central en ciertos estudios arqueológicos y etnoarqueológicos (Hegmon, 2010; Nash, 2009, pp. 219-221). Aunque la escala "micro" que 


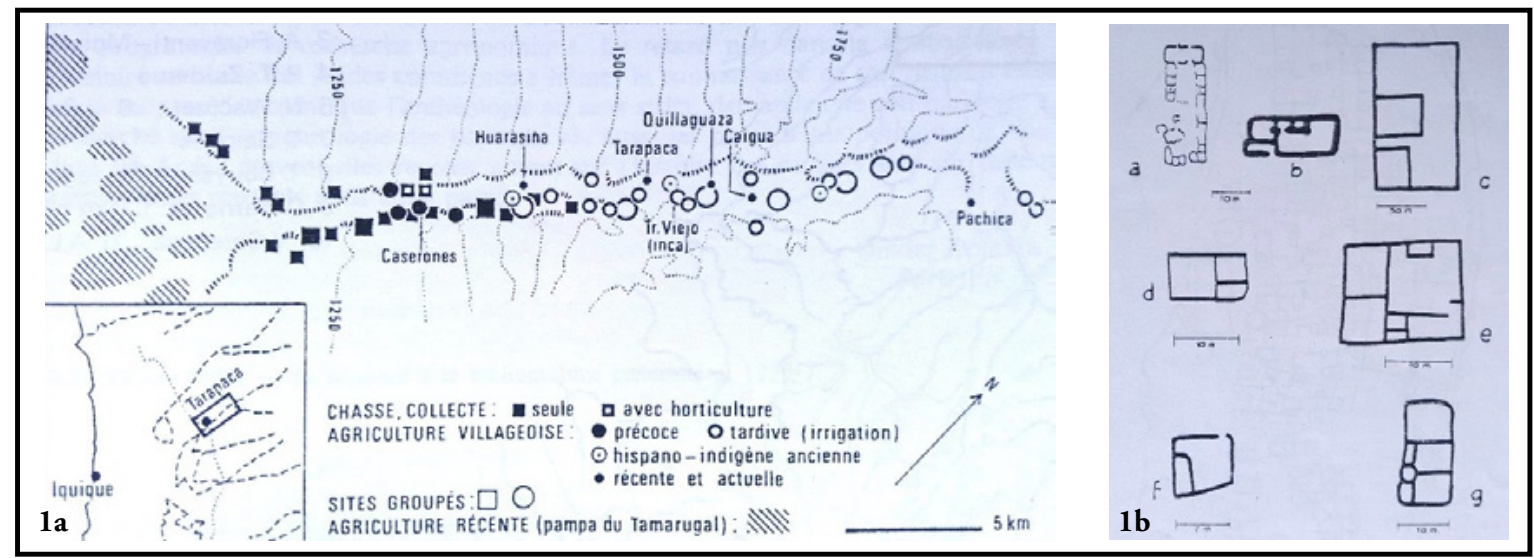

Figura 1. 1a) Ubicación sitios en el valle o quebrada de Tarapacá y 1b) tipos de vivienda de asentamientos registrados en la quebrada de Tarapacá: a) módulo familiar aldea de Huarasiña, b) habitación siglo XIX Huarasiña, c) habitación en Tarapacá Viejo (complejo urbanístico), d) habitación preínca en aldea $\operatorname{Tr}$-13, e) habitación preínca en aldea $\mathrm{Tr}$-13A, f) habitación preínca en aldea Tr-15 (Tilivilca), g) habitación aldea de Caserones (siglo I-XI DC). Fuente: Núñez, L. 1978, Fig. 1: 907; 1979: 200.

define la vivienda o las estructuras residenciales es de gran potencial para comprender y explicar las dinámicas sociales y el establecimiento de delimitaciones espaciales a escala regional o "macro" -donde suelen percibirse los equilibrios y transformaciones en el paisaje ocupado-, dichas interpretaciones debieran estar sustentadas en análisis sistemáticos y comparativos de los patrones y conductas espaciales, los ciclos de vida de la arquitectura y la organización de los asentamientos habitacionales (Holl, 1993, pp. 3-4; Agorash, 1993, pp. 18-21).

Si bien en el área Andina los trabajos han encarado el estudio de la arquitectura doméstica dentro de líneas de investigación relacionadas con la complementariedad económica, relaciones centro-periferia, la formación de grupos de élite, la estabilidad y cambio de la organización familiar y la formación de los grupos étnicos (Aldenderfer y Stanish, 1993, pp. 8-12), en la región de Tarapacá dicha situación -a pesar de ciertos aportes puntuales (Núñez, L., 1978, 1979; Núñez, P., 1983; Zori y Urbina, 2014)-, no ha repercutido sustancialmente, a pesar del caudal de información disponible producto de un ambiente desértico con excelente preservación arqueológica superficial.

En otros casos, los datos relativos a la forma, tamaño, función y riqueza de las viviendas, el estatus dependiente de la elaboración (complejidad), calidad (durabilidad) y energía (trabajo) invertido en ellas y, por último, la reproducción y transformación de estructuras parentales y de la organización familiar constituyen una discusión de suma importancia dentro de la disciplina (Van Gijseghem, 2001; Trebsche, 2009), específicamente el estudio de la relación entre cohabitación/corresidencia y la movilidad o permanencia posmarital de los núcleos familiares con distintos grados de acumulación de riqueza o capital (Blanton, 1994; Nielsen, 2001, 2002).

En este contexto, Kuijt plantea una hipótesis para la transición al neolítico en Jordania, según la cual las comunidades aldeanas precerámicas habrían estado organizadas mediante linajes extensos, donde cualquier sistema de poder compartido y autoridad entre las "casas" de estos linajes habría sido altamente competitivo y prohibido la consolidación de la autoridad por un solo linaje, prohibiendo el uso de arquitecturas residenciales diferenciales o de mayor prestigio que el resto. De este modo, supone que la instauración de reglas sociales para limitar la autoridad y el poder de los individuos y las residencias de estos linajes ("casas") en las aldeas fueran más fuertes, aparentemente mucho más fuertes que la capacidad de los individuos y las "casas" para consolidar el poder y la autoridad en manos de unos pocos (Kuijt, 2000, p. 89).

El mismo autor sugiere que es muy probable que las comunidades, al final de la etapa precerámica du- 
rante período Neolítico, fueron incapaces de desarrollar nuevos medios para organizar posiciones de liderazgo frente a los rápidos cambios en los sistemas económicos, las condiciones ambientales y la agregación de personas en las comunidades aldeanas. Desde esta perspectiva, entonces, el abandono de las comunidades agrarias agregadas puede verse como un experimento fallido en el equilibrio de sistemas anticuados de poder social, en conjunto con la ne- cesidad de desarrollar nuevos medios para organizar y dirigir comunidades urbanas cada vez más grandes con jefes o líderes competitivos (Kuijt, 2000, p. 89).

Desde este marco teórico-analítico, el objetivo de este trabajo es analizar la arquitectura de los asentamientos y sus espacios residenciales, documentando los patrones y transformaciones registradas en el contexto histórico regional de Tarapacá (Figura 2).

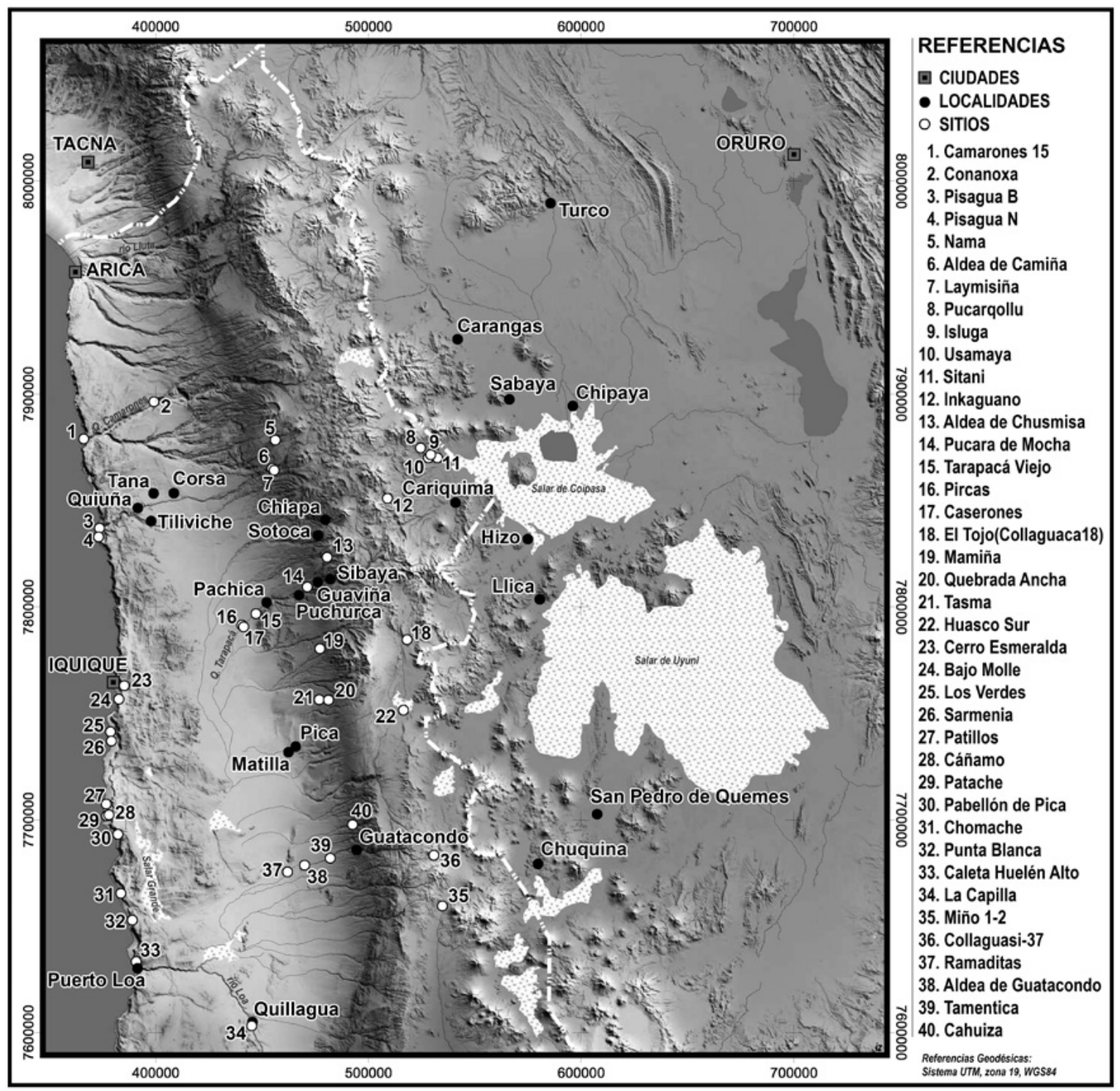

Figura 2. Región de Tarapacá con los principales asentamientos habitacionales mencionados en el texto. 
Según lo hemos propuesto anteriormente (Urbina et al., 2015, 2016), nos interesa explorar los cambios en la estructuración de los espacios domésticos y cómo estos habrían dependido, desde inicios del período Formativo, no solo de las condiciones hidrológicas y climáticas que permitieron la concentración poblacional en los cursos inferiores de las quebradas de Guatacondo, Tarapacá y luego las quebradas altas de la región, sino también -siguiendo los postulados de Engels (2007 [1933], p. 28), Fox (1967) y Fried (1967, pp. 5-9)- de la consolidación gradual de formaciones multifamiliares (linajes), grupos corporativos (sociedades segmentarias) o estamentos funcionarios (estatales) que implementaron, con distintos niveles de éxito y planificación, cambios en la estructura familiar basados en diseños arquitectónicos y segmentación de las viviendas, los cuales en último término modificaron la fisonomía general de los sitios (McGuire y Schiffer, 1983, pp. 284-287; Flannery, 2002, pp. 417-418, 431; Blanton et al., 1996).

\section{Integración regional de la información inter-sitios}

Gran parte de la información arquitectónica, dataciones y levantamientos topográficos que aquí referimos han sido publicados previamente en monografías o reportes parciales (Núñez, 1966, 1979; Cervellino y Téllez, 1980; Meighan y True, 1980; Núñez, P., 1983; Zlatar, 1983; Núñez, P. 1984; Moragas, 1991; Urbina y Adán, 2006; Adán et al., 2007; Berenguer y Cáceres, 2008; Berenguer et al., 2011; Urbina et al., 2011; 2012a, 2015), lo que a la fecha ha permitido una sustantiva comprensión de los patrones de asentamiento durante la transición Arcaico-Formativo y a lo largo del período Intermedio Tardío y Tardío-Colonial (Núñez, L., 2006; Adán y Urbina, 2007, 2010; Núñez y Santoro, 2011; Urbina et al., 2012b; Adán et al., 2013; Zori y Urbina, 2014; Urbina, 2014, 2018).

La investigación regional ha reportado cerca de medio centenar de sitios arqueológicos con arquitectura, cuya distribución abarca un transecto aproximado de $200 \mathrm{~km}$ (Pisagua-Isluga), entre el litoral pacífico y el altiplano chileno-boliviano; mientras que, en sentido norte-sur, se extiende por $250 \mathrm{~km}$ entre la cuenca de la quebrada de Camińa y el río Loa. En el presente estudio, una treintena de sitios presenta datos e índices arquitectónicos confiables para una comparación inter-sitio integrando una amplia variabilidad de tipos de asentamientos y cronologías (Tablas 1 y 2 ).

Si bien cada sitio puede ser definido dentro de un período arqueológico a partir de su fecha de fundación, de acuerdo a la Tabla 1, el lapso ocupacional de los sitios o "longevidad" (fundación y abandono definitivo) indica que asentamientos fundados en el período Arcaico y Formativo fueron ocupados por múltiples generaciones, alcanzando antigüedades relativas entre 700 y 1500 años, en promedio once siglos durante el período Formativo Temprano y nueve siglos durante el Formativo Tardío. Esta afirmación abarca sitios dispersos y aglutinados ubicados en la costa, pampa y quebradas altas, que serán abandonados durante el período Intermedio Tardío. Precisamente, la longevidad de los asentamientos parece cambiar durante el período Intermedio Tardío, cuando los asentamientos habitacionales son ocupados entre 50 y 600 años desde su fundación, en promedio cuatro siglos, mientras que, en el período Tardío, excluyendo Tarapacá Viejo (ca. 6601660 DC), solo alcanzan un promedio de 290 años de ocupación desde el momento fundacional.

Una situación difícil de dirimir es el grado de espontaneidad o planificación de los asentamientos preincaicos en esta región, tema que no ha recibido la atención suficiente. Los grados de aglutinamiento y dispersión pueden ser indicativos para evaluar esta situación si se consideran de modo combinado los índices de densidad y el FOS (Tabla 1). Ambos índices señalan que la longevidad de los sitios dispersos de distinta extensión (10,7-1050 ha) es resultado de estrategias neolocales de instalación de viviendas unitarias o conglomerados de estructuras a lo largo de décadas y siglos consecutivos, producto de grupos con estrategias altamente móviles (Densidad: 0,4-14,9/ FOS: 0,02-6,2\%). De este modo los asentamientos alcanzarían su fisonomía final mediante un crecimiento cuyas reglas de instalación están regidas por la distancia entre las estructuras iniciales 
Tabla 1. Características e índices arquitectónicos por sitio respecto de la periodificación regional.

\begin{tabular}{|c|c|c|c|c|c|c|c|c|c|}
\hline & & Longevidad & Patrón & & & Superficie & & Índices & \\
\hline 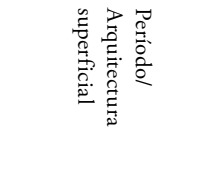 & $\cong$ & 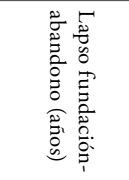 & 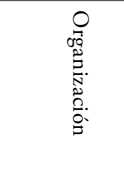 & 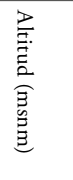 & 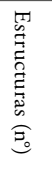 & 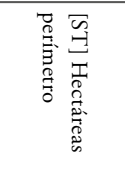 & 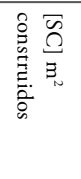 & 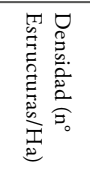 & $\begin{array}{ll}n & 0 \\
G & 0 \\
\vdots & 0 \\
0 & 0 \\
0 & \infty \\
0 & 0\end{array}$ \\
\hline Arcaico Tardío & $\begin{array}{l}\text { Caleta Huelén } \\
42\end{array}$ & 1000 & Aglutinado & 27 & 30 & 0,3 & 71 & 90,9 & 2,2 \\
\hline Formativo Temprano & Ramaditas & 886 & Disperso & 1.120 & 83 & 9,2 & 2.370 & 9,0 & 2,6 \\
\hline Formativo Temprano & Pircas & 865 & Disperso & 1.230 & 562 & 89,9 & 6.594 & 6,3 & 0,7 \\
\hline Formativo Temprano & $\begin{array}{l}\text { Aldea de } \\
\text { Guatacondo }\end{array}$ & 1300 & Aglutinado & 1.380 & 177 & 0,8 & 4.215 & 226,9 & 54,0 \\
\hline Formativo Temprano & Tasma & 1495 & Disperso & 2.500 & 445 & 180,0 & 2.069 & 2,5 & 0,1 \\
\hline Formativo Temprano & $\begin{array}{l}\text { Quebrada } \\
\text { Ancha }\end{array}$ & 945 & Disperso & 2.800 & 163 & 40,0 & 593 & 4,1 & 0,1 \\
\hline Formativo Tardío & Sarmenia & & Disperso & 10 & 8 & 0,3 & 67 & 27,2 & 2,3 \\
\hline Formativo Tardío & Chomache & 640 & Aglutinado & 10 & 5 & 0,02 & 63 & 238,1 & 30,0 \\
\hline Formativo Tardío & Punta Blanca & 850 & Disperso & 22 & 8 & 0,1 & 78 & 64,0 & 6,2 \\
\hline Formativo Tardío & Pisagua N & 1130 & Aglutinado & 50 & 25 & 0,1 & 432 & 277,8 & 48,0 \\
\hline Formativo Tardío & $\begin{array}{l}\text { Caleta Huelén } \\
\text { Alto }\end{array}$ & 920 & Disperso & 70 & 159 & 10,7 & 1.299 & 14,9 & 1,2 \\
\hline Formativo Tardío & Caserones & 1000 & Aglutinado & 1.290 & 646 & 3,8 & 15.996 & 172,3 & 42,7 \\
\hline Intermedio Tardío & Los Verdes & 900 & - & 10 & 1 & - & 13 & - & - \\
\hline Intermedio Tardío & $\begin{array}{l}\text { Pabellón de } \\
\text { Pica }\end{array}$ & 150 & Disperso & 10 & 1 & - & 88 & - & - \\
\hline Intermedio Tardío & Pisagua B & 50 & Disperso & 30 & 8 & 1,0 & 333 & 8,0 & 3,3 \\
\hline Intermedio Tardío & La Capilla & 790 & Aglutinado & 830 & 72 & 0,8 & 1.960 & 96,0 & 26,1 \\
\hline Intermedio Tardío & Carora & - & Disperso & 1.620 & 42 & 1,4 & 799 & 30,9 & 5,9 \\
\hline Intermedio Tardío & Mocha & 100 & Aglutinado & 2.180 & 112 & 0,9 & - & 121,7 & - \\
\hline Intermedio Tardío & Camińa & 600 & Aglutinado & 2.410 & 588 & 3,0 & 9.903 & 194,7 & 32,8 \\
\hline Intermedio Tardío & Jamajuga & 130 & Aglutinado & 2.800 & 135 & 1,2 & 2.136 & 116,4 & 18,4 \\
\hline Intermedio Tardío & Nama & 220 & Aglutinado & 3.100 & 558 & 5,7 & 7.165 & 98,6 & 12,7 \\
\hline Intermedio Tardío & Chusmisa NE & 130 & Aglutinado & 3.310 & 120 & 1,3 & 2.524 & 90,2 & 19,0 \\
\hline Intermedio Tardío & Huasco 1 & 450 & Disperso & 3.810 & 51 & 31,2 & - & 1,6 & - \\
\hline Intermedio Tardío & Husaco Sur & 230 & Disperso & 3.820 & 383 & $1.050,0$ & 2.341 & 0,4 & 0,02 \\
\hline Intermedio Tardío & $\begin{array}{l}\text { Collacagua } 18 \\
\text { (El Tojo) }\end{array}$ & 535 & Disperso & 3.890 & 196 & 70,5 & - & 2,8 & - \\
\hline Intermedio Tardío & Pucar Qollu & 250 & Aglutinado & 3.930 & 586 & 1,8 & 16.028 & 331,1 & 90,6 \\
\hline Tardío & Pisagua Viejo & - & Disperso & 40 & 35 & 14,0 & - & 2,5 & - \\
\hline Tardío & $\begin{array}{l}\text { Tarapacá } \\
\text { Viejo }\end{array}$ & 1000 & Aglutinado & 1.400 & 108 & 3,0 & 16.562 & 35,9 & 55,0 \\
\hline Tardío & Miño 1 & 120 & Disperso & 3.810 & 36 & 1,7 & 2.583 & 21,4 & 15,4 \\
\hline Tardío & Collacagua 19 & 330 & Aglutinado & 3.910 & 35 & 0,4 & - & 81,4 & - \\
\hline Tardío & Miño 2 & 289 & Disperso & 3.930 & 36 & 0,9 & 927 & 39,1 & 10,1 \\
\hline Tardío & Collahuasi 37 & 410 & Disperso & 4.000 & 170 & 59,5 & 4.100 & 2,9 & 0,7 \\
\hline Tardío & Inkaguano & 290 & Disperso & 4.250 & 52 & 0,8 & 1.437 & 63,4 & 17,5 \\
\hline
\end{tabular}


y posteriores, así como por la capacidad máxima de cada unidad doméstica. ${ }^{6}$

Los asentamientos aglutinados (Densidad: 90,2331,1/ FOS: 12,7-90,6\%), por su parte, serían resultado de eventos constructivos en lapsos más breves de edificación y estrategias de mantenimiento y subdivisión más intensivas y planificadas a lo largo de los siglos, donde la ampliación de la vivienda nuclear, mediante métodos aditivos o de estructuras colindantes, aumentaría la capacidad de alberge de estas residencias multifamiliares, conservando el eje de poder en las "casas" más antiguas, elaboradas o amplias del barrio o conglomerado. En consecuencia, las aldeas supondrían la agregación de esos linajes extensos en donde la residencia posmarital se plantea anexa o adjunta a la residencia de los progenitores -una clara demostración de la riqueza y capital social del grupo-, densificando los sitios y aumentando el porcentaje de uso de suelo.

6 De acuerdo con Adán et al. (2011), las unidades aisladas o conglomeradas en sitios como Tasma o Quebrada Ancha permiten apreciar con claridad la regulación de la capacidad de albergue en cada uno de estos tipos de recintos. En Quebrada Ancha, a modo de ejemplo, a juzgar por la variabilidad en los tamaños de los "recintos aislados", los cuales comprenden la totalidad de los rangos de tamaños - desde menos de $1 \mathrm{~m}^{2}$ hasta los 18 $\mathrm{m}^{2}$ y toda la variedad formal de plantas-, estaríamos ante un tipo de estructura que comprende diferentes funciones como áreas de tareas específicas, por ejemplo, para el trabajo lítico, parapetos y otras multifuncionales con un carácter doméstico. En el caso de los conglomerados, se plantean dos hipótesis alternativas: que se trate de complejos multifuncionales correspondientes a unidades domésticas, o bien que su unicidad correspondiera a una congregación de éstas en estructuras de uso multifuncional. Nos inclinamos más bien por la primera opción, puesto que al observar los conjuntos se aprecia que los conglomerados suelen contener recintos de tamaños diferentes, aunque suele ser más frecuente en los conglomerados de tres o más estructuras; éste es el caso de un conglomerado de cinco estructuras presente en Quebrada Ancha, cuyas dimensiones son 7,14; 3,$70 ; 3,12 ; 1,01 ; 1,95$ y $1,33 \mathrm{~m}^{2}$. En cambio, en aquellos compuestos por solo dos estructuras, las dimensiones suelen ser más homogéneas y generalmente de tamaños más pequeños $\left(<3 \mathrm{~m}^{2}\right)$, como lo ejemplifica un conglomerado de dos estructuras cuyas superficies son de 1,48 y $1,81 \mathrm{~m}^{2}$, respectivamente.
Durante el período Tardío o Inca, los asentamientos tienden a grados de planificación que mantienen los índices de densidad en valores bajo 90 estructuras por hectárea y excluyendo asentamientos administrativos de gran envergadura (Tarapacá Viejo), el FOS no sobrepasa el 20\%. Aquí, las viviendas están sometidas a un canon sumamente normado, como veremos en el siguiente apartado, y probablemente no constituyen viviendas permanentes o propias de sus habitantes, sino residencias temporales de funcionarios o tributarios del sistema rotativo de trabajo incaico. Se trata por tanto de residencias ajenas de uso temporal, que virtualmente no son intervenidas o modificadas por adiciones posteriores o subdivisiones.

Respecto de la escala de los sitios. En la franja altitudinal entre 10 y $1.380 \mathrm{msnm}$, la envergadura de los asentamientos aglutinados Formativos se presenta en dos tramos: 1) sitios aglutinados en la costa que exhiben superficies entre 0,02 ha (Chomache) y 0,1 ha (Pisagua $N$ ) para formatos que involucran superficies construidas entre 63 y $432 \mathrm{~m}^{2}$ respectivamente $y, 2)$ sitios con arquitectura pública que ocupan entre 0,8 ha (aldea de Guatacondo) y 3,8 ha (Caserones) y cuya inversión de trabajo se traduce en superficies construidas de 0,42 ha (177 estructuras) y 1,59 ha (646 estructuras) respectivamente. Esta situación cambia radicalmente en el período Intermedio Tardío, cuando los asentamientos aglutinados se ubican entre 830-3.930 msnm y presentan superficies entre 0,8 ha (La Capilla) y 5,7 (Nama) ha, con superficies constructivas que oscilan entre 0,19 ha (La Capilla) y 1,6 ha (Pucar Qollu). En tanto que el período Inca, el único asentamiento aglutinado construido en la región bajo el formato cusqueño parece haber sido Tarapacá Viejo $(1400 \mathrm{msnm})$ con 3 ha de perímetro y 1,6 ha construidas.

La lectura de las Tablas 1 y 2 permite establecer de modo significativo la secuencia de larga duración relativa a la fundación de poblados en la región. Si consideramos los extensos campamentos de arquitectura dispersa, especialmente indicativos de los sistemas de movilidad practicados durante el período Formativo Temprano en el ámbito de la pampa del Tamarugal (1.120-2.800 msnm), a lo largo del Formativo Tardío las ocupaciones asociadas a esta clase 
Tabla 2. Lapsos ocupacionales de los sitios a partir de dataciones absolutas publicadas (C14 y TL).

Fuente: Núñez, 1978; Cervellino y Téllez, 1980; Uribe et al., 2007, Tabla 1: 150; Uribe y Urbina, 2009, Tabla 1: 241; Uribe y Urbina, 2010, Tabla 1: 1322; Berenguer et al., 2011; Urbina et al., 2012a, Tabla 11: 57, Moragas 1993: 29; Salazar et al., 2013: 94; Zori y Urbina 2014, Tabla 2: 220; Urbina 2014; Urbina et al., 2015.

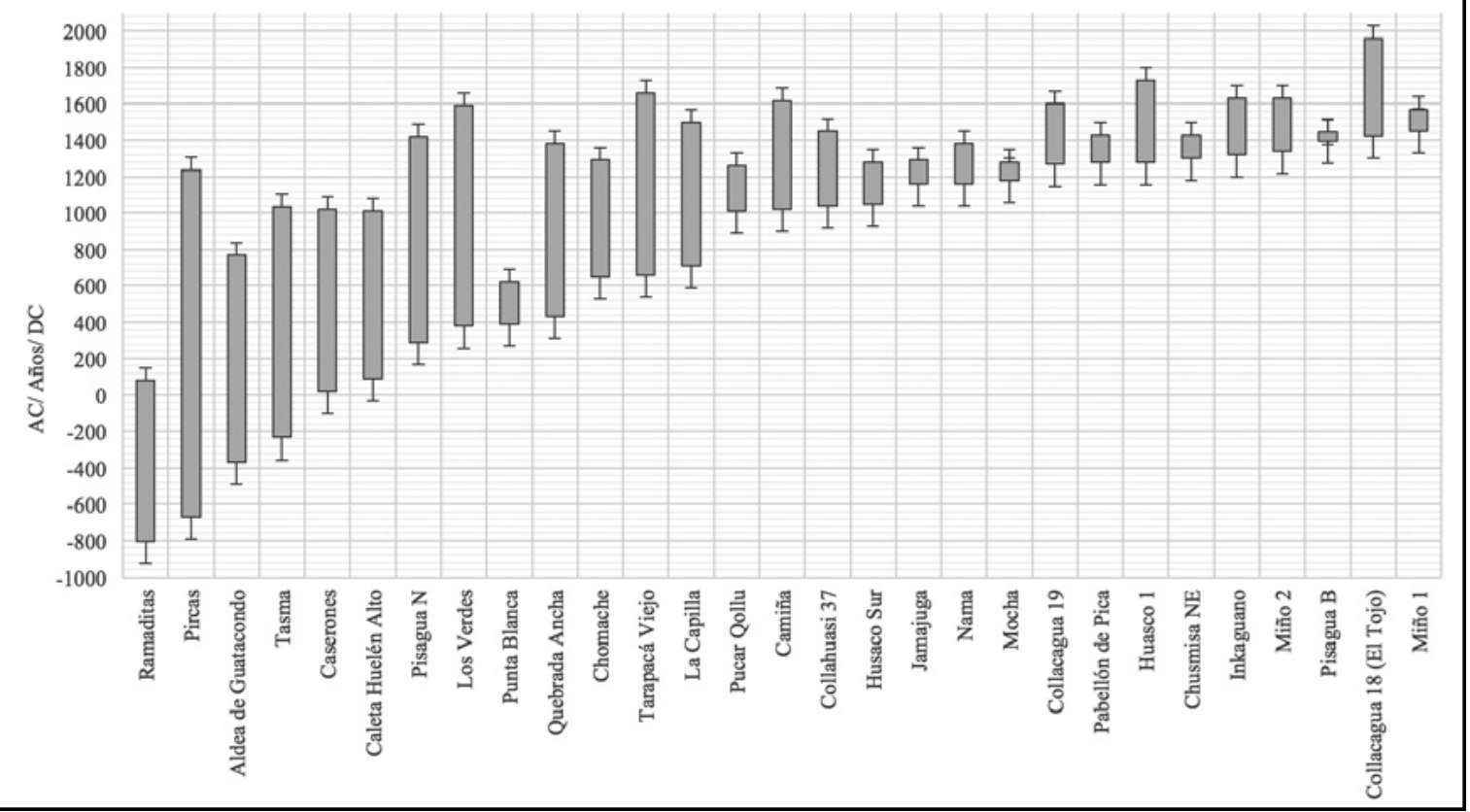

de asentamientos se amplían notablemente hacia la costa adyacente (10-70 msnm), mientras que en el Intermedio Tardío alcanza el altiplano tarapaqueño (3.810-4.250 msnm), ocupando con seguridad los cursos medios y superiores de las quebradas que articulan ambos espacios. Este movimiento es análogo al que se percibe en los asentamientos aglutinados -aldeanos, de primer orden o nivel jerárquico-, aunque durante el período Formativo, diríamos que el eje se desplaza en sentido sur-norte, desde la quebrada de Guatacondo a Tarapacá, y desde dicha quebrada hacia las quebradas altas y el altiplano durante el período Intermedio Tardío.

Es necesario puntualizar que, si bien algunos campamentos del período Formativo se mantuvieron vigentes en la costa y quebradas hasta inicios del período Intermedio Tardío (ca. 900 DC), ciertos asentamientos aglutinados o aldeanos de este período pudieron derivar de ocupaciones establecidas durante el período Formativo Tardío (p.e. La Capilla, Tarapacá Viejo, Camińa y Pucar Qollu).
Respecto de los patrones formales y morfo-funcionales que se derivan de la información presentada en la Tabla 3, la historia arquitectónica de la región reconoce el predominio de viviendas de planta circular y sus derivadas entre fines del Arcaico e inicios del Formativo (Urbina et al., 2011), tanto en sitios dispersos como aglutinados localizados en la costa, pampa y quebradas (10 y $2.800 \mathrm{msnm}$ ), involucrando materiales constructivos como la piedra y el barro (Adán y Urbina 2007; Adán et al., 2013). ${ }^{7}$ Durante el Formativo Tardío, en tanto, el gradual abandono de Guatacondo y el crecimiento de los asentamientos en el curso inferior de la quebrada de Tarapacá, pampa Iluga y la ocupación más intensa

7 Si bien la quebrada de Guatacondo es considerada el epicentro de la Tradición en Barro o de Oasis, debemos indicar que se verifica este tipo de arquitectura en recientes prospecciones en el valle de Quillagua (Pellegrino et al., 2015) y en el litoral tarapaqueño en el sitio Pabellón de Pica (Urbina et al., 2011), donde las dataciones apuntan a una continuidad de esta tradición arquitectónica hasta el siglo XIV-XV DC. 
Tabla 3. Patrones morfo-funcionales por sitio, período y tradición. *Asentamientos aglutinados.

\begin{tabular}{|c|c|c|c|c|c|c|c|c|c|c|c|c|c|}
\hline \multirow[t]{2}{*}{ Sitio } & \multirow[b]{2}{*}{ 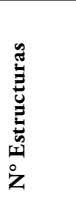 } & \multicolumn{4}{|c|}{ \% patrón morfológico de planta } & \multicolumn{7}{|c|}{ \% rangos de tamańo estructuras } & \multirow{2}{*}{$\begin{array}{c}\text { Tradición } \\
\text { Arquitectónica } \\
\text { predominante }\end{array}$} \\
\hline & & 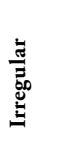 & 苞 & 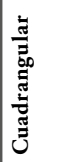 & 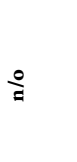 & 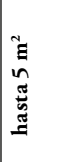 & 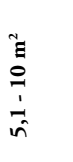 & $\begin{array}{c}1 \\
\Xi \\
0 \\
\mathcal{N} \\
1 \\
\tilde{O} \\
0\end{array}$ & 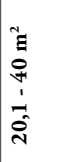 & 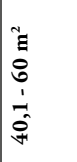 & 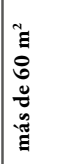 & 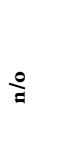 & \\
\hline Caleta Huelén $42^{*}$ & 30 & & 100,0 & & & 66,7 & 33,3 & & & & & & Piedra o temprana \\
\hline Ramaditas* & 83 & 33,73 & 62,6 & 3,6 & & 15,0 & 26,5 & 33,7 & 10,8 & 4,8 & 8,4 & 0,7 & Barro de oasis \\
\hline Pircas & 562 & 1,2 & 64,4 & 8,2 & 25,8 & 60,1 & 16,0 & 13,5 & 5,7 & 2,1 & 2,5 & & Piedra o temprana \\
\hline $\begin{array}{l}\text { Aldea de } \\
\text { Guatacondo* }\end{array}$ & 177 & 55,36 & 32,8 & 9,6 & 2,25 & 17,0 & 30,5 & 32,2 & 14,7 & 1,7 & 1,7 & 2,3 & Barro de oasis \\
\hline Tasma & 445 & 46,5 & 38,0 & 14,8 & 0,7 & 63,4 & 28,5 & 6,3 & 0,7 & & 0,2 & 0,9 & Piedra o temprana \\
\hline Quebrada Ancha & 163 & 37,4 & 46,0 & 16,6 & & 84,1 & 11,7 & 3,1 & 0,6 & & 0,6 & & Piedra o temprana \\
\hline Sarmenia & 8 & 12,5 & 25,0 & 62,5 & & 50,0 & 25,0 & 25,0 & & & & & Costera en Piedra \\
\hline Chomache* & 5 & & & 100,0 & & & 80,0 & 20,0 & & & & & Costera en Piedra \\
\hline Punta Blanca & 8 & 37,5 & & 62,5 & & 25,0 & 37,5 & 37,5 & & & & & Piedra o temprana \\
\hline Pisagua $\mathrm{N}$ & 25 & 24,0 & 12,0 & 64,0 & & 12,0 & 16,0 & 24,0 & 40,0 & 4,0 & & 4,0 & Costera en Piedra \\
\hline Caleta Huelén Alto & 159 & 34,0 & 24,5 & 39,0 & 2,51 & 49,7 & 27,0 & 17,0 & 3,8 & 1,9 & 0,6 & & Piedra o temprana \\
\hline Caserones* & 646 & 9,1 & 6,0 & 84,2 & 0,6 & 24,8 & 21,8 & 22,0 & 14,6 & 8,4 & 7,1 & 1,4 & Caliche o anhidrita \\
\hline Los Verdes & 1 & & & 100,0 & & & & 100,0 & & & & & Costera en Piedra \\
\hline Pabellón de Pica & 1 & & 100,0 & & & & & & & & 100,0 & & Barro de oasis \\
\hline Pisagua B & 8 & 25,0 & & 75,0 & & & & 62,5 & & 25 & 12,5 & & Piedra/ Quincha \\
\hline La Capilla* & 72 & 0,0 & 4,15 & 95,9 & & 43,1 & 6,9 & 9,7 & 11,1 & 11,1 & 15,3 & 2,8 & $\begin{array}{l}\text { Caliche o anhidrita/ } \\
\text { Piedra }\end{array}$ \\
\hline Carora & 42 & 23,8 & 9,6 & 64,3 & 2,3 & 9,5 & 2,4 & 45,2 & 40,5 & 2,4 & 0,0 & & $\begin{array}{l}\text { Quebradeńa o de } \\
\text { Tierras Altas }\end{array}$ \\
\hline Camiña* & 588 & 24,1 & 45,8 & 27,2 & 2,9 & 37,4 & 11,5 & 23,6 & 22,9 & 3,0 & 1,0 & 0,6 & $\begin{array}{l}\text { Quebradeńa o de } \\
\text { Tierras Altas }\end{array}$ \\
\hline Jamajuga* & 135 & 23,7 & 22,2 & 51,8 & 2,3 & 9,6 & 20,0 & 46,0 & 21,5 & 2,2 & & 0,7 & $\begin{array}{l}\text { Quebradeńa o de } \\
\text { Tierras Altas }\end{array}$ \\
\hline Nama* & 558 & 40,7 & 43,34 & 15,9 & & 28,7 & 22,9 & 24,2 & 20,8 & 2,0 & 0,9 & 0,6 & $\begin{array}{l}\text { Quebradeńa o de } \\
\text { Tierras Altas }\end{array}$ \\
\hline Chusmisa NE* & 120 & 25,0 & 30,82 & 44,2 & & 20,8 & 20,0 & 20,0 & 25,0 & 10,0 & 4,2 & & $\begin{array}{l}\text { Quebradeña o de } \\
\text { Tierras Altas }\end{array}$ \\
\hline Husaco Sur & 383 & 21,9 & 63,4 & 14,6 & & 65,3 & 24,0 & 6,8 & 1,0 & & 1,0 & 1,8 & $\begin{array}{l}\text { Quebradeńa o de } \\
\text { Tierras Altas }\end{array}$ \\
\hline Pucar Qollu* & 586 & 29,3 & 41,6 & 28,7 & 0,3 & 43,2 & 20,0 & 17,4 & 9,7 & 2,2 & 7,3 & 0,2 & $\begin{array}{l}\text { Quebradeńa o de } \\
\text { Tierras Altas }\end{array}$ \\
\hline Tarapacá Viejo* & 108 & 0,0 & 0,0 & 100,0 & & & & 12,0 & 36,1 & 11,1 & 40,8 & & Tardía o incaica \\
\hline Miño 1 & 36 & 27,8 & 13,9 & 58,3 & & 25,0 & 25,0 & 22,2 & 16,7 & & 11,1 & & Tardía o incaica \\
\hline Miño 2 & 36 & 11,1 & 13,9 & 75,0 & & 25,0 & 30,6 & 13,9 & 5,6 & 13,9 & 11,1 & & Tardía o incaica \\
\hline Collahuasi 37 & 170 & 12,4 & 45,3 & 41,2 & & 56,5 & 22,4 & 9,4 & 1,2 & 3,5 & 7,1 & & Tardía o incaica \\
\hline Inkaguano & 52 & 7,7 & 30,8 & 59,6 & 1,9 & 25,0 & 34,6 & 28,9 & 3,9 & & 7,7 & & Tardía o incaica \\
\hline
\end{tabular}


del litoral influyen en la propagación de los formatos cuadrangulares en las viviendas de piedra unida con argamasa, anhidrita, barro y quincha (Núñez, L., 1979; Núñez, P., 1983; Urbina et al., 2015). ${ }^{8}$

Esta tendencia cambia y parece volver a la situación precedente durante el período Intermedio Tardío, momento en que la Tradición Quebradeña o de Tierras Altas deja sentir su influencia en los patrones formales de Nama, Camiña y Pucar Qollu -con estructuras ovoidales, elípticas o subcirculares sobre sistemas de terrazas-, señalando el vínculo histórico con las quebradas altas de los Valles Occidentales y el Altiplano Meridional; mientras que, en los asentamientos sureńos, el patrón cuadrangular parece más arraigado a los patrones formativos precedentes y los formatos residenciales propios de la subárea Circumpuneña (Adán y Urbina, 2010). Durante el período Tardío, los diseńos ortogonales utilizados con cierta flexibilidad por los albañiles incaicos elevan nuevamente la representación de las plantas con ángulos rectos, mientras que en general se mantienen en el ámbito altiplánico asentamientos mixtos donde coexisten estructuras de ambos formatos (p.e. Miño 1 y 2, Collahuasi 37 e Inkaguano).

Los rangos de tamaño en los cuales pudieran clasificarse los espacios domésticos en los distintos tipos de sitio y períodos (Tablas 2 y 3 ) ha sido uno de los ámbitos de exploración más complejos de dirimir. Es muy difícil efectuar estimaciones demográficas posibles de ajustar considerando la envergadura $y$ longevidad de los sitios y, más aún, la definición de los espacios domésticos está sometida a variaciones de tamaño y configuración si se considera un período tan extenso de tiempo, razón por la cual los rangos de tamaño que se utilizan como hipótesis funcionales para estimar la capacidad habitacional de los sitios varían según condiciones específicas.

8 Este cambio formal es difícil de interpretar en términos culturales o de innovación tecnológica, puesto que tanto la región de Arica y el salar de Atacama durante el período Medio o bajo la influencia Tiwanaku presentan patrones residenciales similares, con diseños rectangulares o en ángulo o con esquinas ligeramente curvadas. Nuestra opinión es que, pudiendo las tradiciones arquitectónicas vecinas influenciar el proceso registrado en la región de Tarapacá, en ninguna de éstas se registran asentamientos aglutinados y dispersos de la magnitud, densidad y complejidad de los que aquí analizamos.
Con todo, nuestra impresión es que las viviendas pequeńos parapetos, refugios o unidades espaciales aisladas- poseen rangos de tamaño que alcanzan hasta $10 \mathrm{~m}^{2}$, especialmente en aquellos asentamientos dispersos (campamentos), donde el rango bajo 5 $\mathrm{m}^{2}$ alcanza una representación porcentual por sobre el 49-50\% (p.e. Caleta Huelén 42, Pircas, Tasma, Quebrada Ancha, Caleta Huelén Alto y Huasco Sur). Mientras que en los asentamientos aglutinados las viviendas se ubicarían preferentemente en el rango entre $10-20 \mathrm{~m}^{2}$, con representaciones que oscilan entre el 35 y el $66 \%$. Por lo tanto, debe considerarse esta diferencia fundamental entre asentamientos aglutinados, donde las estructuras bajo los $5 \mathrm{~m}^{2}$ pudieran asociarse mayormente a funciones de almacenaje-rituales, y asentamientos dispersos, donde justamente es este rango de tamaño el que cumple funciones de refugio, vivienda semipermanente o transitoria (Adán et al., 2011).

A lo largo del período Formativo, el crecimiento de las superficies de las casas o residencias -los conglomerados y barrios, sus complejas subdivisiones o adiciones y elaboración de los distintos detalles constructivos (techos, paramentos, fundaciones, ventanas, entre otras) - pueden ser descritos principalmente en los asentamientos aglutinados en barro y anhidrita. Allí los conjuntos aglomerados alcanzan grandes proporciones (Adán et al., 2007; Urbina et al., 2012a, 2015) luego de siglos en que las viviendas de los descendientes de un linaje se adjuntan a las viviendas fundacionales, paralelamente a procesos de subdivisión interna, generando tramas compactas que configuran verdaderos barrios y sectores que agrupan una serie de barrios a nivel intra-sitio.

Esta situación cambia drásticamente en el Intermedio Tardío (véanse Figuras 3 y 6) en un proceso que lleva aparejados cambios en las dimensiones de las viviendas y en la inversión de trabajo para construirlas, así como el abandono de las grandes aldeas aledañas a la pampa y la fundación ex novo de múltiples asentamientos aglutinados, sin herencia formativa, en los cursos medios y superiores de las quebradas. En estos nuevos asentamientos las viviendas son diseñadas con menor capacidad, elaboración y complejidad interna y donde la estrategia de residencia neolocal se expresa ahora, a diferencia del período Formativo, dentro de cada asentamiento 
aglutinado. En el siguiente apartado discutiremos precisamente el comportamiento de los patrones residenciales, basados en los formatos de las viviendas, su configuración interna y materiales constructivos, a partir de los cuales es posible discutir los principales hitos de la historia tarapaqueña prehispánica.

\section{Discusión: patrones residenciales y arquitectura doméstica}

\section{Viviendas de patrón circular en torno a patios centrales}

De acuerdo a la información analizada, un primer tipo de espacio doméstico que podemos distinguir en la secuencia cronológica está definido por unidades residenciales de forma circular $u$ oval en piedra, de amplia distribución altitudinal (10-2800 msnm), y otras, de mayor elaboración e inversión de trabajo que utilizan el barro como principal materia prima (10-1380 msnm), ya sea dispersas/aisladas o en aglomerados en torno a patios centrales de tamańos y complejidad variables (Figura 3a-h y 4 ).

En el caso de los asentamientos en piedra (campamentos de Caleta Huelén Alto, Pircas, Tasma, Quebrada Ancha y Huasco Sur), están representadas centenares de viviendas unitarias y otras más aglomeradas, reflejo de agrupamientos de familias nucleares establecidas, transitoria o estacionalmente, de modo aislado o disperso sobre grandes extensiones de terreno reocupados durante siglos. Un antecedente de este patrón estaría indicado por el sitio Caleta Huelen 42, habitado por cerca de un milenio (2830-1830 AC) según las dataciones disponibles (Zlatar, 1983, p. 25).

La singularidad de los grandes conglomerados y barrios de planta circular en Ramaditas y Guatacondo respondería dentro de la historia regional a la conformación material y simbólica de linajes o "casas", en una demostración de manejo tecnológico y riqueza, escenificada siguiendo una novedosa práctica congregacional y de gran escala para la época. Aquí, las tareas y espacios cotidianos se agregan en torno a espacios públicos destinados a ceremonias colectivas y las labores constructivas se relacionan directamente con la mantención de los espacios comunitarios: selección de bloques de piedra, preparación de adobones y barro, revestimiento o estucado de las paredes y decoración en fresco de secciones interiores de recintos, empotramiento de postes de prosopis de gran diámetro en el centro de estructuras techadas o en ramadas parciales. De acuerdo con la tesis de Urton (1988), la historia de construcción y mantención de los muros de esas plazas es al mismo tiempo la historia organizacional de sus habitantes.

La configuración del patrón de asentamiento regional definida por campamentos extensos y centros aldeanos en el delta de las quebradas endorreicas (borde oriental de la pampa del Tamarugal) sugiere que la conformación arquitectónica de la aldea/poblado de Guatacondo tendría una funcionalidad específica no solo destinada a la vida sedentaria. Tendría como objetivo fijar un espacio para eventos públicos-comunitarios, modificando los patrones de alta movilidad que predominan en el ámbito desértico regional desde el período Arcaico. Probablemente supone la instauración de cierto orden calendárico que requiere reorganizar el trabajo de múltiples unidades domésticas en torno a cultígenos adaptados a los ámbitos cálidos e irrigados del desierto a partir del siglo II AC (García et al., 2014). ${ }^{9}$ La correlación clásica entre innovaciones/adopciones agrícolas y nucleamiento aldeano permanente parece de este modo tener débiles evidencias que la confirmen.

9 Según García y colaboradores (2014, pp. 52-53), los restos vegetales recuperados de las aldeas formativas de Tarapacá documentan dimensiones básicas de la vida social, principalmente alimentación, artesanía y construcción. Por una parte, la diversidad de alimentos presentes fue relevada en tres tipos de espacios, que incluyen contextos de preparación y consumo, pozos de almacenaje y contextos ceremoniales. Éstos corresponden a frutos recolectados en los bosques y quebradas, así como productos obtenidos de los campos agrícolas, identificados como molle (Schinus molle), algarrobo (Prosopis sp.), chañar (Geoffroea decorticans), maíz (Zea mays), calabaza (Lagenaria siceraria), poroto (Phaseolus vulgaris), pallar (Phaseolus lunatus), quinoa (Chenopodium quinoa) y amaranto (Amaranthus sp.). Estas últimas evidencias conformarían, hasta el momento, los contextos agrícolas más tempranos de la pampa del Tamarugal, especialmente los cultivos fechados en la aldea Guatacondo (quinoa, calabaza y maíz) entre 160 AC y 70 DC. 
a

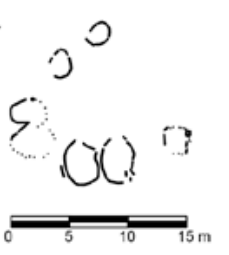

d

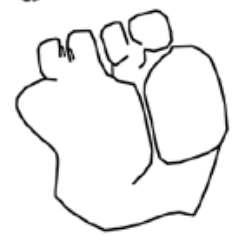

g

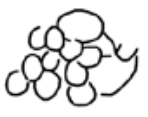

b<smiles>C1COC2(CO1)OCCO2</smiles>

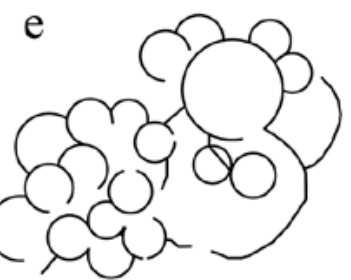

h

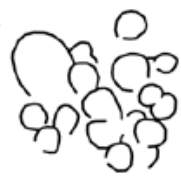

c

f

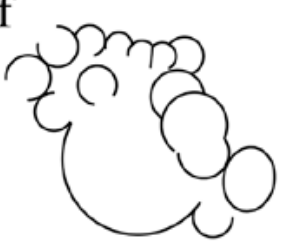

$\mathrm{i}$

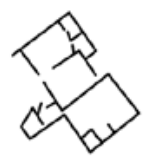

j<smiles></smiles>

k

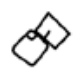

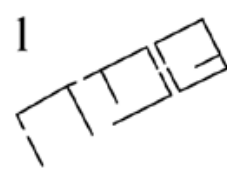
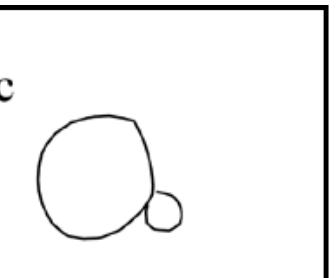


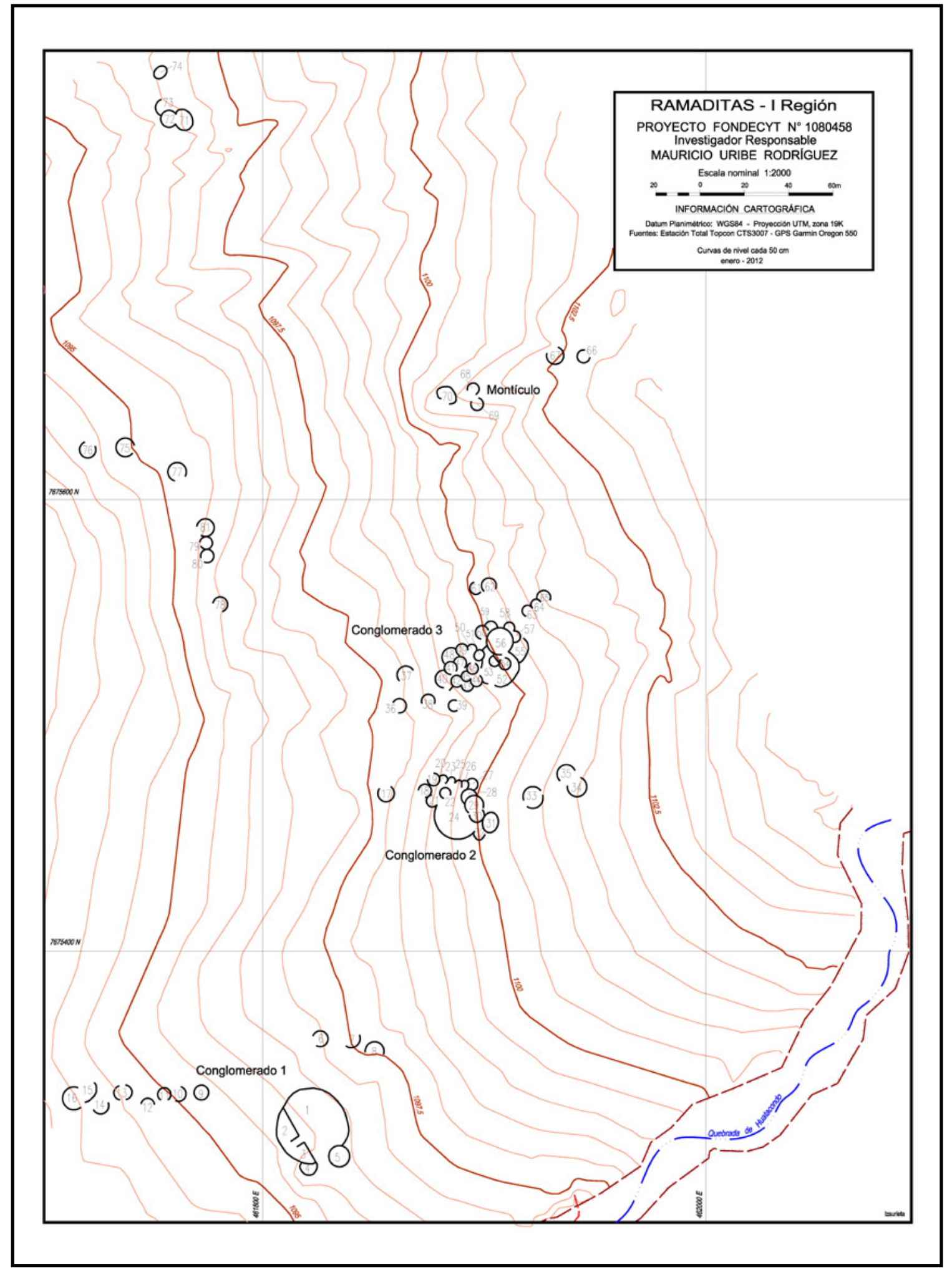

Figura 4. Aldea de Ramaditas, quebrada de Guatacondo. Conglomerados de barro-piedra y estructuras 
En términos cronológicos, el patrón circular en piedra y barro que utilizan aldeas segmentadas/dispersas se desarrolla en una primera época a partir del siglo IX-VIII AC en Ramaditas y Pircas -suponemos que también en el valle de Quillagua y Pica-, y ya en el siglo VII AC se encuentra habitado el lugar donde luego se levantará la gran plaza oval del poblado de Guatacondo, el principal centro político de la región hasta el siglo IV DC. Este patrón arquitectónico aldea/poblado comenzaría a ser abandonado en la pampa a inicios de la Era, sin embargo, aquello parece no haber afectado significativamente la permanencia de asentamientos campamentales, caletas o refugios/parapetos costeros, en la pampa y la precordillera.

\section{Viviendas de patrón rectangular colindantes y con subdivisiones}

El segundo tipo de espacio doméstico identificado en la región utiliza unidades residenciales en la forma de recintos modulares de planta rectangular $\mathrm{u}$ ortogonales, que utilizan como materia prima piedra (10-2.800 msnm) y anhidrita y barro (830$1.290 \mathrm{msnm}$ ) y se emplazan sobre terrenos planos o de pendiente suave (Figura 3i-m). Los recintos presentan accesos mediante pasillos, subdivisiones internas y adiciones exteriores de otros recintos o estructuras similares, maximizando la superficie habitable y el uso de materiales constructivos elaborados, como bloques de anhidrita trabajados o bolones de piedra seleccionados, argamasa preparada de gran cohesión, postes de prosopis empotrados en los muros y estuco o revestimiento.

Asentamientos dispersos construidos en piedra, de naturaleza multicomponente (Figura 5), esto es, con viviendas de planta circular y rectangular, se ubican en las quebradas precordilleranas (p.e. Tasma y Quebrada Ancha), la pampa (Pircas) y en la desembocadura del río Loa (Caleta Huelén Alto). Al mismo tiempo se establecen los primeros asentamientos aglutinados en litoral pacífico con plantas cuadrangulares y rectangulares (p.e. Pisagua N, Los Verdes[?], Sarmenia y Chomache), a veces con muros ligeramente curvados. Corresponden a pequeñas caletas/aldeas junto a playas mayormente rocosas próximas a colonias de aves, moluscos y guaneras, las cuales se distinguen por ser unidades rectangulares contiguas o módulos ortogonales con

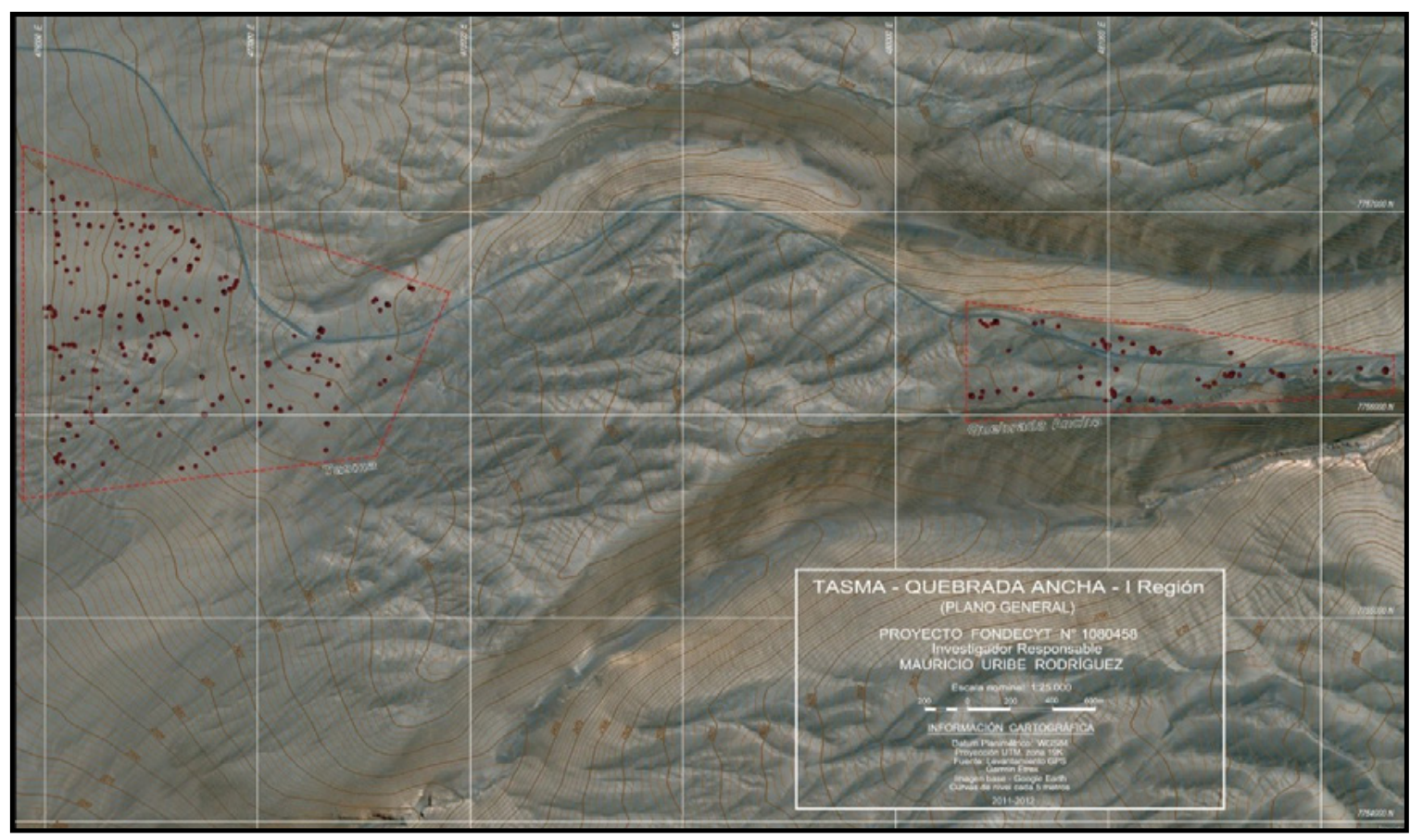

Figura 5. Polígonos de dispersión de estructuras de patrón rectangular y circular en Tasma (izquierda) y Quebrada Ancha (derecha). 
subdivisiones internas, pisos preparados y entierros fundacionales de cabezas de mamíferos marinos o cánidos bajo los muros.

El patrón de asentamiento que caracteriza al período Formativo Tardío comprendería en consecuencia la extensión de los campamentos en las quebradas prepuneñas y el fortalecimiento de las ocupaciones aglutinadas y de pequeña escala en el litoral desértico. A diferencia del período anterior, las estrategias corresidenciales entre localidades en la costa, pampa y quebradas se fortalecen, y con ello la complementariedad de los recursos marítimos/litorales y forestales/agrícolas y pecuarios que parece estar sustentada en una marcada identidad en los patrones arquitectónicos de las viviendas que se utilizan en todas estas zonas.

En el caso de Caserones, los extensos barrios intramuros sugieren grados extremos de cohesión de las comunidades o linajes, cuestión notable si se considera la extensión territorial disponible fuera del área construida. A pesar de la extensión, densidad y ocupación de suelo que expresan los barrios en la planimetría del asentamiento -que alcanzan superficies mayores a $2000 \mathrm{~m}^{2}$ y en varios casos más de 80 estructuras colindantes (Urbina et al., 2012, p. 51)-, estimamos que la restricción de acceso y crecimiento de los barrios, así como la reducción de escala de los espacios públicos tienen que ver con situaciones de competencia y niveles críticos de acumulación de poder, riqueza y prestigio por parte de estos linajes o familias extensas.

Allí donde se ejecutan grandes obras comunales planeadas y con fines urbanísticos, espacios ceremoniales abiertos y cerrados a modo de templos/patios ceremoniales (Vidal, 2012, pp. 235-238; Urbina et al., 2012a, p. 53), se expone y escenifica su propia orgánica, particularmente la posición y preeminencia de cada familia extensa/linaje o comunidad, su procedencia y lugar en el espacio, respecto de los recursos de la pampa y de otras familias, incluyendo aquellas que no acceden a espacios poblados como Caserones. En este caso, parece cierto que la presencia de plazas públicas y templos parece institucionalizar los lazos de parentesco y colaboración para la ejecución de importantes fiestas calendáricas y colectivas asociadas a la explotación de bosques de prosopis y extensas áreas irrigables en el desagüe de la quebrada de Tarapacá (pampa Iluga) y la quebrada de Aroma. Sin embargo, el espacio habitable luego de siglos de crecimiento ha generado una competencia decidida entre los barrios (linajes) que componen el sitio y por ello se imponen medidas restrictivas al crecimiento y densificación desmedida que pudiera desequilibrar las relaciones sociopolíticas, construyéndose un extenso doble muro perimetral hacia el siglo VI DC.

La regulación económica que involucra el trabajo de recolección, procesamiento y almacenaje de semillas y vainas, así como el trabajo maderero (Adán et al., 2013), permiten comprender la gran inversión de energía que supuso la edificación de este gran complejo aldeano y las causas de las tensiones generadas por un sistema económico-social que requirió medidas de autorregulación, posiblemente las mismas que detonaron su abandono.

A partir del abandono de Caserones, los nuevos asentamientos comienzan a exhibir diseños de planta de crecimiento regular $\mathrm{u}$ ortogonal y división bipartida en barrios, los cuales a diferencia de Caserones, se organizan en sectores o "mitades" separadas por senderos rectos, calles o vías de circulación longitudinales, señalan el gradual surgimiento de parcialidades o "sayas", al modo de los ayllus andinos (Núnez, P., 1983, p. 35). Producto de una reorganización de las relaciones laborales y sociales entre unidades domésticas, los patrones residenciales en las aldeas tarapaqueñas post formativas siguen fomentando importantes grados de aglutinamiento posmarital (bajo neolocalismo) a partir de la formación de una nueva unidad doméstica, lo cual puede apreciarse nítidamente en las planimetrías de estos sitios (Figura 31-m).

\section{Viviendas de muros curvos o rectos conglomeradas sobre terrenos aterrazados}

Las aldeas tarapaqueñas que estudia Patricio Núñez (1983, Figura 31-m) señalarían el inicio de una dinámica de segmentación de la sociedad tarapaqueña post formativa y una fragmentación de los nodos geopolíticos que ostentaron mayores grados de inversión arquitectónica durante el primer milenio de la Era. El abandono de éstos nodos hacia fines del 


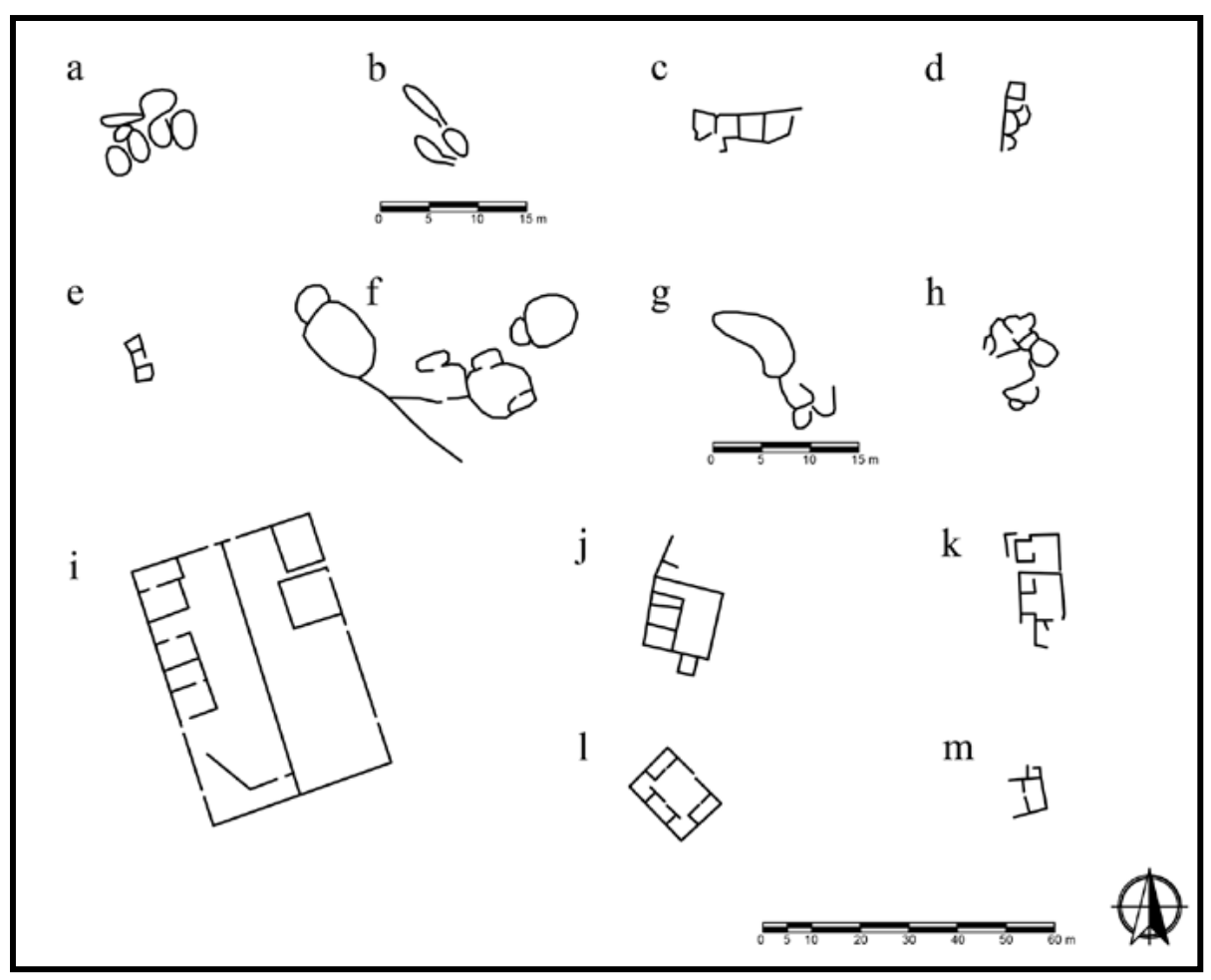

Figura 6. Patrones de estructuras domésticas de Tradición Quebradeńa y Tardía. Período Intermedio Tardío: a) Camiña, b) Nama, c) Pucar Qollu, d) Chusmisa NE, e) Collahuasi-37, f) El Tojo (Collacagua-18), g) Collacagua-19, h) Huasco-1. Período Tardío: i) Cancha C-Tarapacá Viejo, j) Collahuasi-37, k) Miño-2, l) Inkaguano. Período Inca-Colonial: m) PT0273-Quillagua.

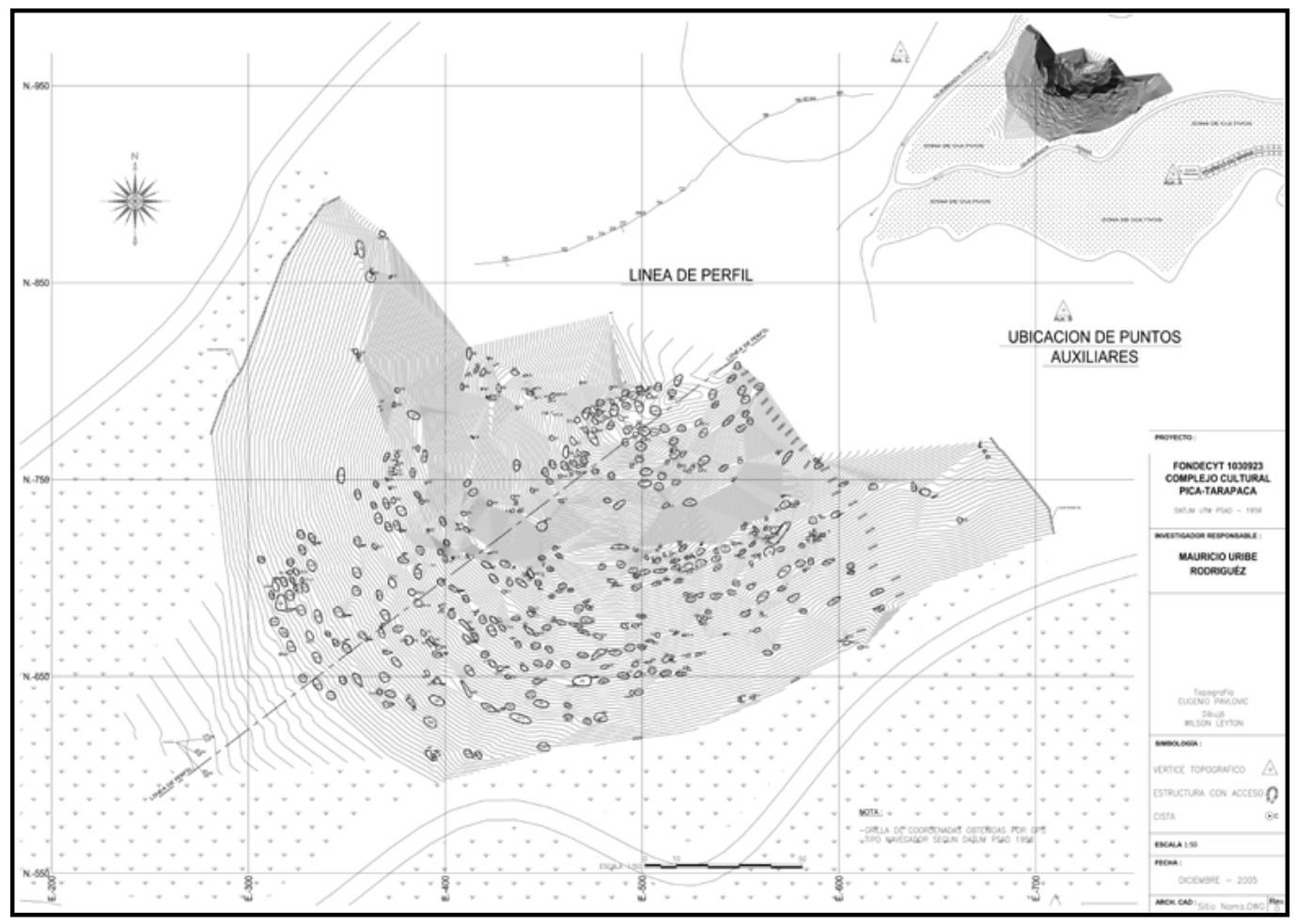

Figura 7. Levantamiento topográfico de la aldea de Nama. 
siglo X DC y la fundación de nuevos asentamientos en los cursos medios y superiores de las quebradas (Núńez, L., 1979, 1984) se relacionaría directamente con una ocupación más intensa de terrazas fluviales o promontorios junto a fondos de valles o quebradas mediante sistemas estancieros y una menor intensidad en el uso de los extensos campamentos ubicados en las rutas de circulación pampa-tierras altas (Pircas, Tasma-Quebrada Ancha, Cahuiza y Huasco Sur).

Al iniciarse el período Intermedio Tardío, el patrón de asentamiento involucrará al menos tres niveles jerárquicos (Adán y Urbina, 2010; Urbina, 2014) correspondientes a asentamientos aglutinados de distinta envergadura, crecimiento espontáneo y bajo nivel de planificación -con plazas en la cumbre de los dos primeros niveles-,ubicados preferentemente en la zona precordillerana (Camiña, Chusmisa y Jamajuga) y en el altiplano tarapaqueño (Pucar Qollu) (Urbina y Adán, 2006). Las viviendas utilizan como material constructivo bloques de piedra en estado natural o levemente trabajadas (pirca seca). Son de diseño expeditivo, sin embarg han requerido del acondicionamiento del terreno en pendiente mediante el desmonte y nivelación del terreno en terrazas. Las formas, distribución y patrón de aglutinamiento de las viviendas demuestran una disminución del tamaño interior de los espacios domésticos y de los patios familiares o comunales (Figura 6ah), como puede observarse en la planta general de Nama (Figura 7).

Se constata una progresiva constitución neolocal de las unidades domésticas a nivel intra-sitio, mientras que en aldeas como Chusmisa NE y Jamajuga se aprecian conglomerados de estructuras rectangulares adosadas (Figura 6c-d) que siguen los patrones tarapaqueños del Formativo Tardío, pero a menor escala. De cualquier modo, a nivel regional ocurre una dinámica inter-sitio que a partir del siglo XIII DC permite a las familias ocupar distintos valles, franjas longitudinales y pisos ecológicos mediante estrategias corresidenciales propias del patrón pueblo-estancia/caletas, razón por la cual los asentamientos presentan combinaciones o esquemas mixtos en términos de patrones formales de planta y una mayor variabilidad en los rangos de tamaño.
El trazado de los asentamientos aglutinados es el resultado de un crecimiento espontáneo o no planificado de los espacios domésticos. La escala (superficie total) que exhiben y el número de estructuras indican una importante intensidad de uso de espacios acotados por distintas unidades residenciales, durante varios siglos inclusive. Las aldeas de segundo y tercer orden presentan dos modalidades, una de tierras bajas vinculada a la Tradición Arquitectónica de Oasis, también llamada Tradición del Desierto y, la segunda, relativa a la llamada Tradición de Tierras Altas o Quebradeña, cuya expresión también involucra a las aldeas mayores o de primer orden.

Estas aldeas se emplazan sobre cerros islas o laderas de pendiente abrupta, sobre el fondo de valles agrícolas y próximos a yacimientos mineros; presentan en ciertas ocasiones un reducto abierto en la cumbre a modo de plaza, el cual articula a su alrededor niveles de terrazas escalonadas con unidades domésticas en pequeños conglomerados de viviendas, cocinas y patios edificados en piedra. Estos conglomerados se disponen y comunican mediante vías de circulación dendríticas y en anillos en torno a la plaza de cumbre.

Con todo, a partir del siglo X DC, las viviendas reflejarían situaciones de fisión social, presión demográfica y fragmentación política (p.e. dispersión del poder), causa de la amplificación del espectro de asentamientos aglutinados distribuidos en los distintos pisos ecológicos. De este modo se formarán nuevas comunidades basadas en aglomeraciones de unidades familiares de baja y mediana escala, que poseen y comparten residencias en localidades salpicadas en el territorio regional y macrorregional; grupos que a su vez mantendrían lazos de parentesco sanguíneo o político (p.e. compadrazgo) a corta y larga distancia entre ellas y con unidades sociales mayores.

El período Intermedio Tardío se caracterizaría finalmente por una progresiva segmentación de las unidades familiares durante cinco siglos posteriores al siglo IX DC, acompañado del debilitamiento de los linajes que habitaron el delta y la pampa del Tamarugal junto al desagüe de la quebrada de Tarapacá. Este proceso se percibe por una estrategia 


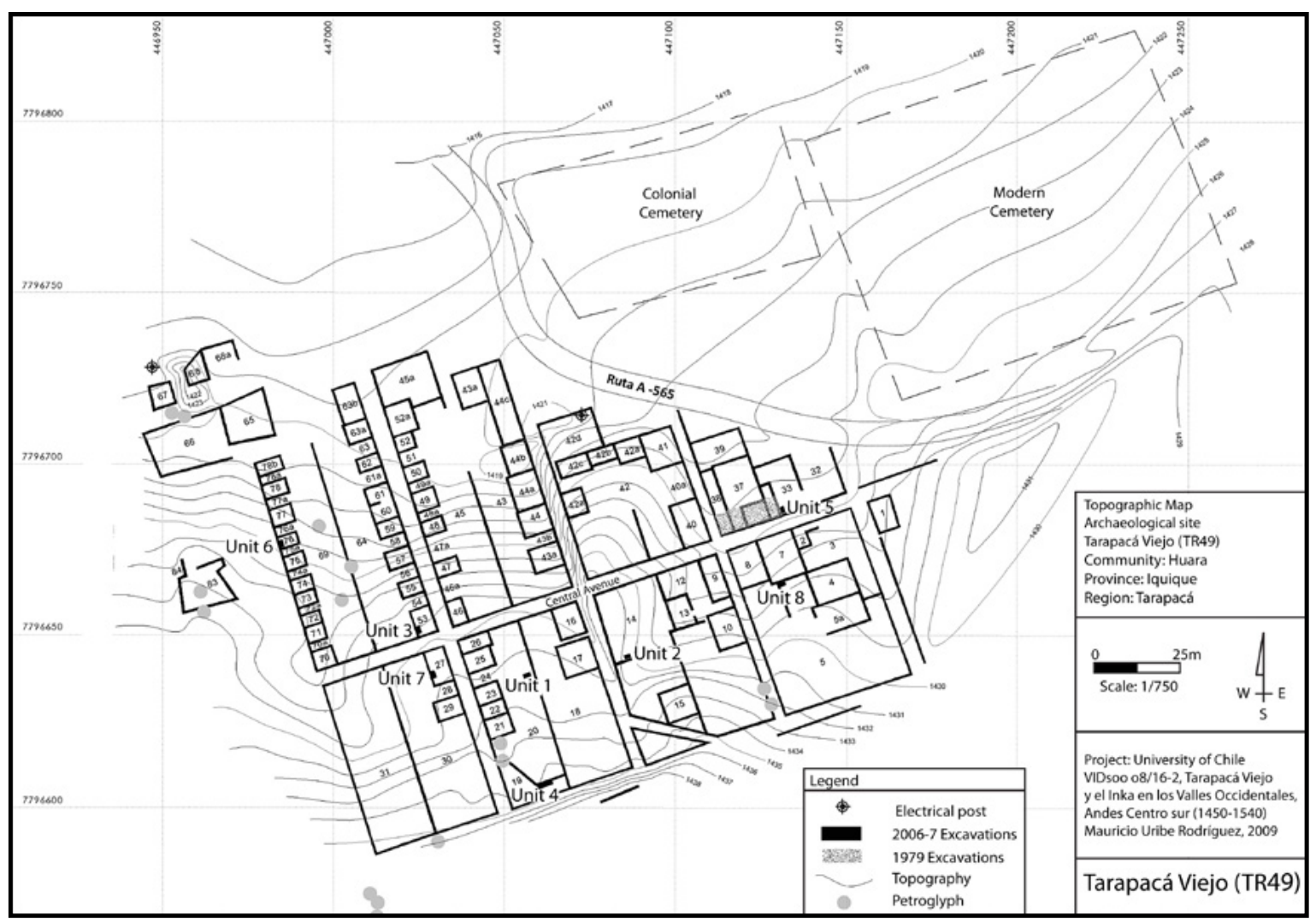

Figura 8. Diseño ortogonal de planta en Tarapacá Viejo. Fuente: Zori y Urbina, 2014.

de residencia neolocal que abarca toda la región e implica el surgimiento de diversos linajes nucleados políticamente, al modo de jefaturas o cacicazgos inter-aldeanos, articulados a su vez por una red de pequeños poblados, estancias o instalaciones distantes donde las unidades residenciales se configuran de acuerdo condiciones locales y la especialización económica del asentamiento (Figura 6f-h).

\section{Residencias de planta ortogonal sobre terrenos planos}

Este patrón corresponde en su mayoría al observado en asentamientos del período de expansión del Tawantinsuyo, viviendas dispuestas o asociadas a asentamientos locales, conformando asentamientos mixtos (Inca-local), fenómeno que a nivel regional ocurre especialmente sobre "estancias" ubicadas en la franja altiplánica tarapaqueña (Berenguer y Cáceres, 2008). Dentro de este grupo se incluye el asentamiento sobre el cual se edificó íntegramente Tarapacá Viejo, la instalación administrativa de trazado urbano más relevante de las tierras bajas a nivel regional (Figura 8).

En general, las instalaciones incaicas -especialmente aquellas ubicadas en las tierras altas- se caracterizan por una notable diversidad funcional y por el aprovechamiento de asentamientos residenciales preexistentes, cuya historia constructiva se inicia con seguridad en el siglo XIII DC, con la excepción del sector B6 de Collahuasi 37 (1040 DC). Específicamente, la edificación de instalaciones de estilo incaico (Miño 2), aquellas que combinan patrones locales e incas (Inkaguano, Collahuasi 37 y Miño 1), asentamientos con remodelaciones moderadas (Huasco 1) y, finalmente, la ocupación de sitios locales sin modificaciones arquitectónicas (Collacagua 18, Huasco 2 y 4) configuran el patrón de asentamiento regional durante este período, el que a pesar de estar concentrado en la franja altiplánica, parece estar supeditado a la cabecera político-administrativa instalada en las tierras bajas (Tarapacá Viejo) (Uribe y Urbina, 2010). 


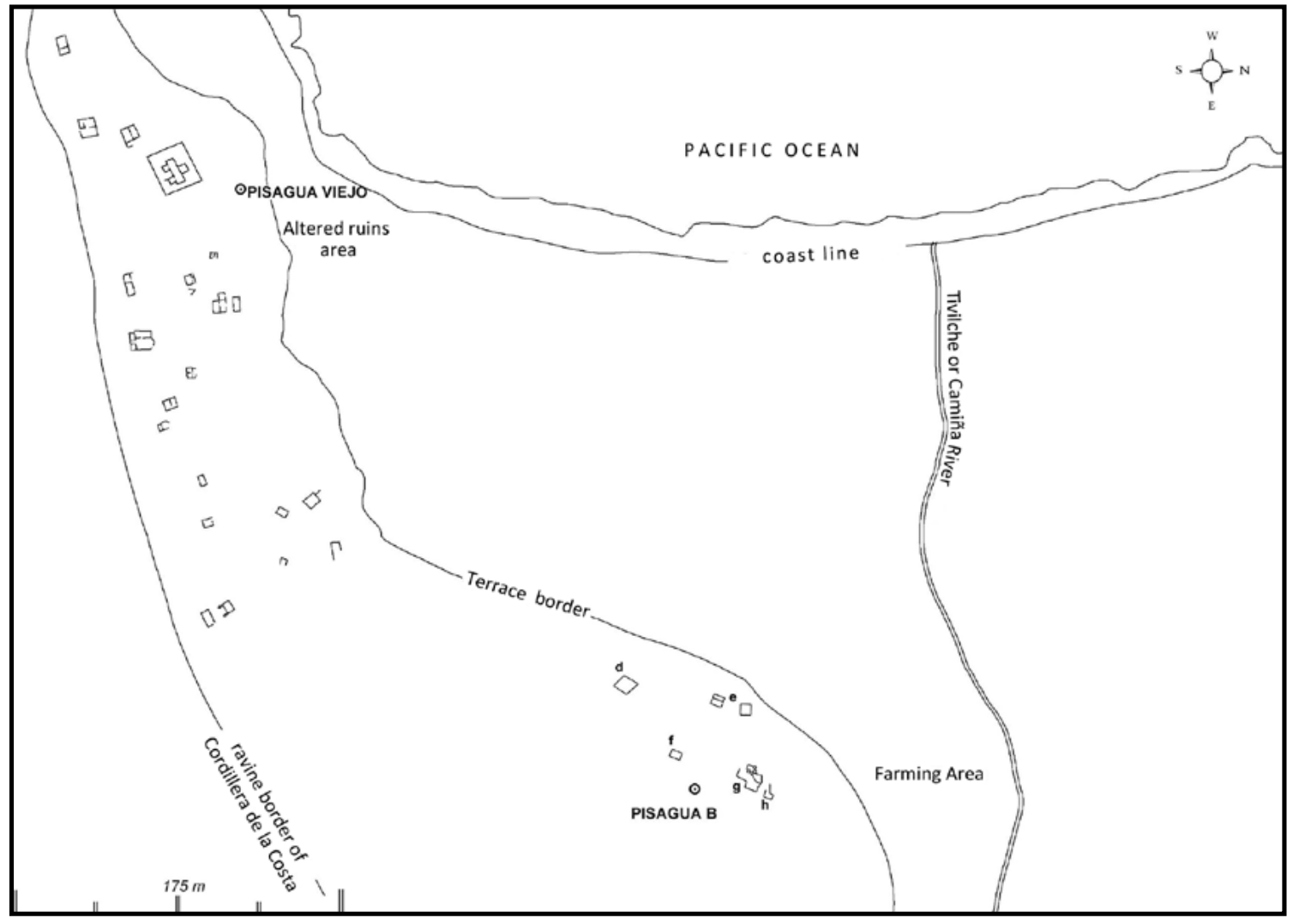

Figura 9. Planimetría de Pisagua Viejo y Pisagua B. Fuente: Urbina et al., 2012, Fig. 8, p. 295.

En este sentido, notamos que la ocupación más intensa registrada en esta clase de asentamientos se inicia en pleno siglo XV, extendiéndose hasta la segunda mitad del siglo XVII, momento en el cual fueron progresivamente abandonados, debido a causas diversas, entre las que figura la aplicación progresiva de las políticas toledanas (ca. 1570 DC) destinadas a concentrar a la población local, propiciando el traslado y abandono de sus poblados tradicionales hacia nuevos asentamientos coloniales con planta en damero denominados reducciones o pueblos de indios (Núñez, P., 1984; Urbina, 2018, pp. 356-369).

Las viviendas de estilo incaico y probablemente aquéllas más tempranas del período Colonial (siglo XVI-XVII) herederas de esta tradición, corresponden a residencias o alojamiento provisorios que siguen el patrón de RPCs (p.e. Collahuasi 37 e Inkaguano/Incamarca), o canchas de gran tamaño con estructuras rectangulares adosadas o inscritas en perímetro interior (p.e. Tarapacá Viejo y Co- llahuasi 37), así como estructuras rectangulares con un pequeño patio exterior de la misma forma (Pisagua Viejo, Miño 2, sitio PT0273, Pellegrino et al., 2015) (Figura 7i-m). ${ }^{10}$ Esta mixtura entre los patrones locales, incaicos e hispano-coloniales puede apreciarse con mayor nitidez en sitios costeros como Pisagua Viejo (Figura 9), donde las viviendas rectangulares aisladas o conglomeradas se dispersan en torno a una iglesia delimitada por un muro perimetral (Núñez, 1970).

Por lo general, en estos sitios las viviendas poseen un solo acceso, usualmente de perfil trapezoidal y sus tamaños oscilan entre 20 y $40 \mathrm{~m}^{2}$. En algunos se identifican callancas o galpones utilizados como albergues

10 La cancha corresponde a la unidad básica de la arquitectura incaica. Se trata de un recinto amplio de planta rectangular en cuyo interior se emplazan tres o más edificaciones en torno a un patio central. El acceso a la cancha suele ser por un vano en el muro que define a la estructura (Hyslop, 1990, p. 17). 
para actividades ceremoniales o administrativas, regularmente asociados a plazas públicas de gran tamaño, las que permanecieron en uso durante el siglo XVI e incluso hasta tiempos recientes (Inkaguano).

Los análisis arquitectónicos y etnohistóricos demuestran que mientras la expansión del Tawantinsuyo implicó la centralización regional en Tarapacá Viejo, sociedades segmentarias jerarquizadas distribuidas en todo el ámbito regional fueron sometidas diferencialmente a alianzas matrimoniales y políticas mediadas por funcionarios incaicos. $\mathrm{Al}$ mismo tiempo que algunas comunidades eran erradicadas de sus áreas de residencia o se ejercía la completa o parcial reconstrucción de asentamientos, como las remodelaciones de estancias, se mantuvieron amplios sectores geográficos (tramos de la costa, valles y cuencas altiplánicas) bajo patrones residenciales propios del período Intermedio Tardío (ca. 9001450 DC) (Berenguer et al., 2011; Urbina, 2014).

La invasión hispana, a mediados del siglo XVI, intentó no solo ocupar la infraestructura incaica -caminos, alojamientos, centros mineros, poblados, adoratorios-, sino reducir las múltiples parcialidades indígenas dispersas en el vasto territorio y contralar de ese modo la fuerza de trabajo de los tributarios que iba a ser depositada al interior del asentamiento colonial, la reducción o el "pueblo de indios" (Urbina, 2018). ${ }^{11} \mathrm{Al}$ parecer, los habitantes de las manzanas occidentales de Tarapacá Viejo, a pesar de dicha política reduccional, siguieron vi-

11 En teoría, a los grupos o comunidades andinas se les pensó asignar sectores específicos dentro de la traza de estos nuevos asentamientos, dando así cabida a una homologación frecuente entre ayllu y barrio (Durston, 1999, pp. 80-81). Como indica Cummins (2002, p. 214), en los pueblos de indios diseñados por la política toledana a fines del siglo XVI (ca. 1570), la intrusión en la vida no se limitó al ámbito de la doctrina cristiana. La traza del asentamiento también incidía directamente en las relaciones sociales de la familia, la cual estaba íntimamente relacionada con la reordenación espiritual del sujeto andino. De esta manera, se buscaba inhibir toda actividad e interacción entre parientes cercanos que, hasta esa fecha, eran facilitadas por los espacios contiguos e interconectados de la cancha inca. El único acceso, que además era público, de las nuevas viviendas coloniales podía ser vigilado por la fuerza pública para, de esta forma, instaurar las normas hispanas que regulaban la dinámica familiar e inculcar la (percepción de) decencia. viendo dentro de los límites de los antiguos complejos de diseño incaico, hacían uso de los espacios comunes donde acostumbraban compartir las labores de manufactura y de tipo doméstico, aunque el foco de atención se había dirigido al exterior, a la calle, donde su comportamiento podía ser vigilado y evaluado según su apego a la nueva normativa jurídica y doctrinal hispana (Zori y Urbina, 2014, p. 228).

\section{Conclusiones}

Para finalizar este trabajo queremos ofrecer tres reflexiones sobre las materias de mayor trascendencia en el estudio de la arquitectura doméstica y la formación de asentamientos en la región de Tarapacá.

En primer lugar, si bien en distintos puntos se reconocen dinámicas de agregación y nucleamiento que conllevan el surgimiento de poblados o aldeas, situación que parece estar relacionada con el crecimiento de las superficies habitables de las viviendas y de los conglomerados residenciales, así como con la aparición de arquitectura comunitaria y pública, es notorio que existieron localidades donde se perciben procesos inversos, donde la tendencia a la dispersión y segmentación de las unidades domésticas es constante. Por ello, la tesis de un progresivo aglutinamiento de los asentamientos en la medida que avanza el período Formativo no es sostenible desde el punto de vista de un estudio sistemático de la arquitectura del período, ni menos que ese proceso de concentración residencial sea una consecuencia directa del surgimiento de la agricultura en la pampa del Tamarugal y sus afluentes.

En este trabajo hemos planteado que, solo desde una perspectiva regional, los patrones de asentamiento (Tablas 1 y 3) y los tipos de unidades domésticas (Figuras 3 y 6) que caracterizan el extenso arco temporal entre fines del período Arcaico e inicios del período Colonial pueden ser comprendidos integralmente. Junto con las distinciones propias del análisis arquitectónico tradicional, hemos definido con mayor detalle las estrategias residenciales de sus habitantes (neolocal $\mathrm{o}$ aditiva posmarital), las cuales pudieron combinarse de diversas maneras dentro de asentamientos planificados o de crecimiento espontáneo, ya sea generado configuraciones sumamente aglutinadas en la fase fi- 
nal de ocupación o permaneciendo dispersos a lo largo de varios siglos. El análisis presentado documenta cambios históricos decisivos, a nuestro entender, en la estructura de parentesco y en la organización de las agrupaciones o comunidades tarapaqueñas, los cuales hemos intentado referenciar a formatos residenciales específicos y período de la secuencia histórica regional, esperando que los períodos de transformación más pronunciados puedan luego ser mejor analizados disponiendo de otros indicadores.

En tercer lugar, el cambio de una estrategia residencial neolocalista, que permite la formación de asentamientos dispersos, a una de aglomeración posmarital, que asegura la aglomeración de las unidades familiares descendientes, parece ser el punto crucial en la formación de los primeros núcleos aldeanos durante el período Formativo Temprano y que, con posterioridad al abandono de estos últimos, alcanzaría límites críticos en los extensos barrios de Caserones, revelando altos grados de competencia y disputas políticas entre familias extensas y linajes hereditarios dentro de la región. Esta competencia pareciera ser resuelta siglos adelante mediante políticas de reordenamiento en mitades para regular el conflicto y mecanismos de segmentación en nuevos núcleos poblados aguas arriba los cursos de valles y quebradas, permitiendo reactivar la movilidad y la fundación de nuevos núcleos poblacionales que se mantendrían ocupados durante el período Inca e incluso durante los primeros siglos Coloniales, y donde las estrategias neolocales cobran nuevamente fuerza.

\section{Agradecimientos}

A todos los colegas que trabajaron en las tareas de prospección, fichaje de arquitectura, levantamientos topográficos y excavaciones desde el año 2004 a 2016. A Xochitl Inostroza y Juan Pablo Ferreiro por la invitación a participar en esta publicación sobre familias indígenas. A las comunidades indígenas y habitantes de la región de Tarapacá que han permitido el acceso a sus sitios patrimoniales. A las y los colegas de la Comisión de Comisión de Patrimonio Arqueológico del Consejo de Monumentos Nacionales. A Constanza Chamorro por la elaboración de las láminas. Este artículo es resultado de los proyec- tos FONDECYT 1130279, 1080458 y 1030923 , así como de la Beca CONICYT de Doctorado en Chile 21090211 sostenida por el primer autor.

\section{Referencias citadas}

Adán, L., y Urbina, S. (2007). Arquitectura Formativa en San Pedro de Atacama. Estudios Atacameños. Arqueología y Antropología Surandinas, 34, 7-30.

Adán, L., y Urbina, S. (2010). Arquitectura quebradeña del Complejo Pica-Tarapacá: modos de hacer, opciones de diseño, rasgos significativos y decisiones funcionales. Actas del XVII Congreso Nacional de Arqueología Chilena, tomo II, 865-876, Valdivia.

Adán, L., Urbina, S., y Pellegrino, C. (2011). Arquitectura de las quebradas prepuneñas de Tarapacá. Informe Técnico compilado por Mauricio Uribe. Proyecto FONDECYT 1080458

Adán, L., Urbina, S., Pellegrino, C., y Agüero, C. (2013). Aldeas en los bosques de Prosopis: Arquitectura residencial y congregacional en el período Formativo tarapaqueño (900 AC-900 DC). Estudios Atacameños. Arqueología y Antropología Surandinas, 45, 75-94.

Adán, L., Urbina, S., y Uribe, M. (2007). Arquitectura pública y doméstica en las quebradas de Pica-Tarapacá: asentamiento y dinámica social en el Norte Grande de Chile (900-1450 DC). En Nielsen, A. E., Rivolta, M. C., Seldes, V., Vázquez, M. M., y Mercolli, P. (Comps.). Procesos Sociales Prehispánicos en el Sur Andino. La vivienda, la comunidad y el territorio. Colección Historia Social Precolombina. Tomo 1 (pp. 183-206). Córdoba: Editorial Brujas.

Aldenderfer, M., y Stanish, C. (1993). Domestic architecture, household archaeology, and the past in South Central Andes. En Aldenderfer, M. (Ed.). Domestic architecture, ethnicity, and complementarity in the South-Central Andes (pp. 1-12). Iowa: University of Iowa Press.

Angorash, K. (1993). Archaeological Considerations on Social Dynamics and Spatial Pattern Development of Traditional Settlements. En Holl, A., y Levy, T. (Eds.). Spatial Boundaries and Social Dynamics: Case Studies from Food-Producing Societies (pp. 7-24). Ann Arbor: International Monographs in Prehistory. 
Berenguer, J., y Cáceres, I. (2008). Los inkas en el altiplano sur de Tarapacá: el Tojo revisitado. Chungara. Revista de Antropología Chilena, 40(2), 121-143.

Berenguer, J., Sanhueza, C., y Cáceres, I. (2011). Diagonales incaicas, interacción interregional y dominación en el altiplano de Tarapacá, norte de Chile. En Núñez, L. y Nielsen, A. (Eds.). Ruta, Arqueología, Historia y Etnografía del Tráfico sur Andino (pp. 247-283). Córdoba: Encuentro Grupo Editor.

Bermann, M. (1993). Continuity and Change in the Household Life at Lukurmata. En Aldenderfer, M. (Ed.). Domestic Architecture, Ethnicity, and Complementarity in the South-Central Andes (pp. 114-135). Iowa: University of Iowa Press.

Blanton, R. (1994). Houses and households: A comparative study. New York: Plenum Press.

Blanton, R., Feinman, G., Kowalewski, S., y Peregrine, P. (1996). A dual-processual theory for the evolution of Mesoamerican civilization. Current Anthropology, 37(1), $1-14$.

Canziani, J. (2009). Ciudad y territorio en los Andes. Contribuciones a la historia del urbanismo prehispánico. Lima: Pontificia Universidad Católica del Perú.

Chang, K. C. (1968). Settlement Archaeology. Palo Alto, California: National Press Books.

Chang, K. C. (1976). Nuevas perspectivas en arqueología. Madrid: Alianza Editorial.

Cervellino, M., y Téllez, F. (1980). Emergencia y desarrollo de una aldea prehispánica de Quillagua, Antofagasta. Contribución Arqueológica, 1, 1-235.

Cummins, T. (2002). Forms of Andean Colonial Towns, Free Hill, and Marriage. En Lyons, C. y Papadopoulus, J. (Eds.). The Archaeology of Colonialism (pp. 199-240). Getty Research Institute.

Durston, A. (1994). Un régimen urbanístico en la América Hispana colonial: el trazado en damero durante los siglos XVI y XVII. Historia, 28, 59-115.

Engels, F. 2007 (1933). El origen de la familia, de la propiedad privada y del Estado. Buenos Aires: Editorial Claridad.
Flannery, K. (2002). The origins of the village revisited: From nuclear to extended households. American Antiquity, 67, 417-433.

Fox, R. (1967). Sistemas de parentesco y matrimonio. Madrid: Alianza Universidad.

Fried, M. (1967). The Evolution of Political Society. New York: Random House.

García, M., Vidal, A., Mandakovic, V., Maldonado, A., Peña, M. P., y Belmonte, E. (2014). Alimentos, tecnologías vegetales y paleoambiente en las aldeas formativas de la Pampa del Tamarugal, Tarapacá (ca. 900 AC-800 DC). Estudios atacameños. Arqueología y Antropología Surandinas, 47, 33-58.

Hegmon, M. (Comp.). (2010). The Archaeology of Tribal Social Formations: Selections from American Antiquity and Latin American Antiquity, 1982-2006. Washington D.C.: Society for American Archaeology,

Holl, A. (1993). Introductory note to spatial boundaries and social dynamics: rounds, recycling, and the buildup of an upward spiral. En Holl, A. y Levy, T. (Eds.). Spatial Boundaries and Social Dynamics: Case Studies from FoodProducing Societies (pp. 1-6). Ann Arbor: International Monographs in Prehistory.

Hyslop, J. (1990). Inca settlement planning. Austin: University of Texas Press.

Knapp, B. (Ed.). (1992). Archaeology, Annales and Ethonohistory. Cambridge: Cambridge University Press.

Kuijt, I. (2000). People and space in early agricultural villages: exploring daily lives, community size, and architecture in the Late Pre-Pottery Neolithic. Journal of Anthropological Archaeology, 19, 75-102.

McGuire, R., y Schiffer, M. (1983). A theory of architectural design. Journal of Anthropological Archaeology, 2, 227-303.

Meighan, C., y True, D. (1980). Prehistoric trails of Atacama: Archaeology of northern Chile. Monumenta archaeologica, 7. Los Angeles, CA: The Institute of Archaeology, University of California.

Moragas, C. (1993). Antecedentes sobre un pukara y estructuras de cumbre asociadas a un campo de geoglifos en la 
quebrada de Tarapacá, área de Mocha, I Región. Boletín del Museo Regional de la Araucanía, 4. Tomo II, 25-39.

Muńoz, I. (1993). Spatial dimensions of complementary resource utilization at Acha 2 and San Lorenzo. En Aldenderfer, M. (Ed.). Domestic Architecture, Ethnicity and Complementary in the South-Central Andes (pp. 94-102). Iowa: Iowa Press.

Nash, D. (2009). Household Archaeology in the Andes. Journal of Archaeological Research, 17(3), 205-261.

Nielsen, A. (1995). Architectural performance and the reproduction of social power. En Skibo, J., Walker, W., y Nielsen, A. (Eds.). Expanding archaeology (pp. 47-66). Salt Lake City: University of Utah Press.

Nielsen, A. (2001). Evolución del espacio doméstico en el Norte de Lípez (Potosí, Bolivia) ca. 900-1700 DC. Estudios Atacameños, 21, 41-61.

Nielsen, A. (2002). Asentamientos, conflicto y cambio social en el altiplano de Lípez (Potosí, Bolivia). Revista Española de Antropología Americana, 32, 179-205.

Núñez, L. (1966). Caserones 1, una aldea prehispánica del norte de Chile. Estudios Arqueológicos, 2, 25-29.

Núñez, L. (1970). Descubrimiento de la aldea española: 'Pisagua Viejo' (Provincia de Tarapacá). Ancora, 52-58. Antofagasta: Universidad de Chile.

Núñez, L. (1978). L'evolution millenaire d'une valle: peuplement et resources a Tarapacá. En Watchtel, N., y Murra, J. (Eds.). Annales. Économies, Sociétés, Civilisations (pp. 906-920). París: CNRS.

Núñez, L. (1979). Emergencia y desintegración de la sociedad Tarapaqueña: riqueza y pobreza en una quebrada del Norte Chileno. Atenea, 439, 163-213.

Núñez, L. (1984). Tráfico de complementariedad de recursos entre las tierras altas y el Pacífico en el área Centro Sur Andina. Tesis Doctoral, tomo II. Universidad de Tokio, Japón.

Núñez, L. (2006). Asentamientos formativos complejos en el centro-sur andino: cuando la periferia se constituye en núcleo. Boletín de Arqueología PUCP, 10, 321-356.

Núñez, L., y Santoro, C. (2011). El Tránsito Arcaico-Formativo en la Circumpuna y Valles Occidentales del Centro
Sur Andino: Hacia los Cambios "Neolíticos". Chungara. Revista de Antropología Chilena, 43(1), 487-530.

Núñez, P. (1983). Aldeas tarapaqueńas, notas y comentarios. Chungara, 10, 29-37.

Núñez, P. (1984). La antigua aldea de San Lorenzo de Tarapacá, Norte de Chile. Chungara, 13, 53-66.

Pellegrino, C., Urbina, S., Izaurieta, R., y Adán, L. (2015). Arquitectura doméstica en la Pampa del Tamarugal, región de Tarapacá, Andes Centro-Sur. Poster presentado en el XX Congreso Nacional de Arqueología Chilena, Sociedad Chilena de Arqueología, Concepción.

Rapoport, A. (1972). Vivienda y Cultura. Barcelona: Editorial Gustavo Gili.

Salazar, D., Berenguer, J., y Vega, G. (2013). Paisajes minero-metalúrgicos inkaicos en Atacama y el altiplano sur de Tarapacá (norte de Chile). Chungara. Revista de Antropologia Chilena, 45(1), 83-103.

Salazar, J. (2008). Aportes de Gordon R. Willey a la comprensión histórica de la arqueología americana. Comechingonia Virtual, 4, 245-254.

Stanish, C. (1989). Household Archaeology: Testing Models of Zonal Complementarity in the South-Central Andes. American Anthropologist, 91, 7-24.

Trebsche, P. (2009). Does form follow function? Towards a methodical interpretation of archaeological buildings features. World Archaeology, 41(3), 505-519.

Trigger, B. (1968). The determinants of settlement patterns. En Chang, K. C. (Ed.). Settlement archaeology (pp. 53-78). Palo Alto, California: National Press Books.

Trigger, B. (1981). Arqueología como ciencia histórica. Boletin de Antropología Americana, 4, 55-89.

Urbina, S. (2014). Asentamientos, poblaciones y autoridades de Tarapaca, siglos XVy XVI (ca. 1400-1572). Tesis para optar al grado de Magíster en Historia, mención Etnohistoria. Facultad de Filosofía y Humanidades, Departamento de Ciencias Históricas. Universidad de Chile.

Urbina, S. (2018). Poblaciones y autoridades de Tarapaca. Desde la incorporación al Tawantinsuyo hasta la organización del Estado Colonial (siglos XV-XVII). Tesis para 
optar al grado de Doctor en Historia, mención Historia de Chile. Facultad de Filosofía y Humanidades, Departamento de Ciencias Históricas. Universidad de Chile.

Urbina, S., y Adán, L. (2006). Construcciones de uso público y su distribución en las quebradas tarapaqueñas durante el Período Intermedio Tardío (900-1450 DC). Boletín de la Sociedad Chilena de Arqueología, 39, 19-34.

Urbina, S., Adán, L., Moragas, C., Olmos, S., y Ajata, R. (2011). Arquitectura de asentamientos de la costa de Tarapacá, norte de Chile. Estudios Atacameños. Arqueología y Antropología Surandinas, 41, 63-96.

Urbina, S., Adán, L., y Pellegrino, C. (2012a). Arquitecturas Formativas de las quebradas de Guatacondo y Tarapacá a través del proceso aldeano (ca. 900 AC-1000 DC). Boletín del Museo Chileno de Arte Precolombino, 17(1), 31-60.

Urbina, S., Adán, L., y Vidal, E. (2012b). Architecture in the Coastal Desert. Andean Past, 10, 289-294.

Urbina, S., Adán, L., Pellegrino, C., y Vidal, E. (2015). Formaciones aldeanas en zonas desérticas de Tarapacá: innovación social y cambio histórico (XI AC-XIII DC). Actas del XIX Congreso Nacional de Arqueología Chilena (pp. 223-230), Arica.

Urbina, S., Adán, L., Pellegrino, C., y Vidal, E. (2016). Early village formation in desert areas of Tarapacá, Northern Chile (Eleventh Century B.C.-Thirteenth Century AD). Andean Past, 12, 188-202.

Uribe, M. (2006). Arqueología de Pica-Tarapacá (norte de Chile): Reflexiones acerca de la complejidad y desigualdad social en los Andes Centro Sur (1000-1450 DC). Estudios Atacameños, 31, 91-114.

Uribe, M. (2009). El Período Formativo de Tarapacá y su cerámica: avances sobre complejidad social en la costa del norte grande de Chile (900 a.C.- 800 d.C.). Estudios Atacameños. Arqueología y Antropología Surandinas, 37, 5-27.
Uribe, M., y Urbina, S. (2009). Cerámica y arquitectura pública en el Camino del Inka del desierto de Atacama (río Loa, Norte Grande de Chile). Número especial Cerámica y Procesos Sociales en los Andes prehispánicos. Revista Chilena de Antropología, 20, 227-260.

Uribe, M., y Urbina, S. (2010). Tarapacá Viejo: Historia ocupacional de un centro incaico en los Valles Occidentales del norte de Chile. Actas del XVII Congreso Nacional de Arqueología Argentina. Tomo III, 1321-1326, Mendoza.

Urton, G. (1988). La arquitectura pública como texto social: La historia de un muro de adobe en Pacariqtambo, Perú (1915-1985). Revista Andina, 6(1), 225-261.

Van Gijseghem, H. (2001). Household and family at Moche, Peru: An analysis of building and residence patterns in a Prehispanic Urban Center. Latin American Antiquity, 12(3), 257-273.

Vidal, E. (2012). Etnoarqueología de la fiesta andina: El caso de la región cultural de Tarapacá. Actas del XVIII Congreso Nacional de Arqueología Chilena (pp. 229-240), Valparaíso.

Willey, G., y Phillip, P. (1958). Method and Theory in American Archaeology. Chicago: University of Chicago Press.

Willey, G. (1968). Settlement archaeology: an appraisal. En Chang, K. C. (Ed.). Settlement Archaeology (pp. 208226). National Press Books.

Yaeger, J., y Canuto, M. (2000). Introducing an archaeology of communities. En Canuto, M., y Yaeger, J. (Eds.), The Archaeology of Communities. A New World Perspective (pp. 1-15). New York: Routledge.

Zlatar, V. (1983). Replanteamiento sobre el problema Caleta Huelén 42. Chungara, 10, 21-28.

Zori, C., y Urbina, S. (2014). Architecture and empire at Late Prehispanic Tarapacá Viejo, Northern Chile. Chungara. Revista de Antropología Chilena, 46(2), 211-232. 